\title{
SEEDLING SURVIVAL IN FOREST RE-VEGETATION SITES WITHIN WELLINGTON PENINSULA
}

BY

VICTOR ANTON VALADES

A thesis submitted to the Victoria University of Wellington in fulfilment of the requirements for the degree of Master in Ecological Restoration.

School of Biological Sciences

Faculty of Sciences

Victoria University of Wellington

June 2013 
Supervisors:

\section{Heiko Wittmer.}

Senior Lecturer at School of Biological Sciences. Victoria University of Wellington.

\section{Stephen Hartley.}

Senior Lecturer at School of Biological Sciences. Victoria University of Wellington.

Victor Anton Valades: Seedling survival in forest re-vegetation sites within Wellington peninsula, (c) June 2013 
Transplanting native seedlings is a widely used restoration tool to enhance biodiversity in urban areas. Due to labour and economic needs of this tool, it is crucial to maximise the survival rates of the transplanted seedlings. In this research, I monitored, over a six month period, the status of wineberry (Aristotelia serrata), cabbage tree (Cordyline australis) and lemonwood (Pittosporum eugenioides) seedlings in their initial years after transplanting. The seedlings, up to 4 years old, were located in 11 forest re-vegetation sites in Wellington city, New Zealand. Using mixed effects models to predict the mortality probability of each species, I analyse the relative importance that variables (e.g. soil conditions or grass competition) have in the mortality of the seedlings. Lemonwood seedlings experienced the lowest mortality rates $(<2 \%)$, independent of age. The models predicting probability of mortality of wineberry and cabbage tree indicate that grass competition and water availability are crucial variables in the mortality of these species during the initial 6 months after transplanting. Combinations of plant size (e.g. height) and certain environmental variables (e.g. soil conditions or slope) crucially affect mortality of wineberry and cabbage trees from one to three years of age. Based on these results, I provide recommendations, such as appropriate planting date and ideal length of maintenance tasks, to maximise survival rates of native plants within the first years after transplanting. A longer monitoring period and similar research of other species are required to assist forest re-vegetation groups in Wellington city achieving more cost- and labour-efficient re-vegetation management. 

The completion of this project was made possible through the support and encouragement of my supervisors Dr. Heiko Wittmer and Dr. Stephen Hartley, my family and Amy. Thanks to Mauro, Chema, Diego, Jay, Mike, and Emma for assisting with the planting. I would also like to thank colleagues and my supervisors for their patience while assisting me to understand the difficult task of writing a thesis in a second language.

A special thanks to the Wellington Botanical Society and the Centre for Biodiversity and Ecological Restoration from Victoria University of Wellington for their financial support. Lastly, thanks to the members from Wellington City Council, local community groups and the Victoria University bug club that contributed information and feedback, making this study possible. 

CONTENTS

Abstract $\quad$ i

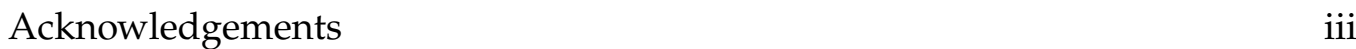

List of Figures $\quad$ vii

List of Tables viii

Acronyms $\quad$ ix

1 INTRODUCTION

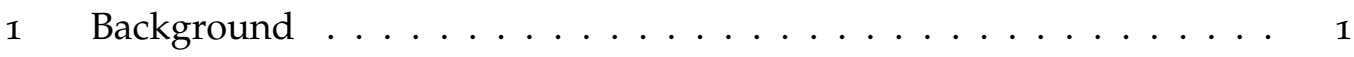

2 Forest re-vegetation projects in Wellington city . . . . . . . . . . 3

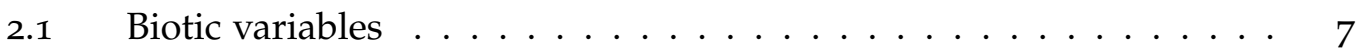

2.2 Abiotic variables ................... . . 8

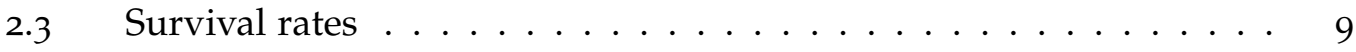

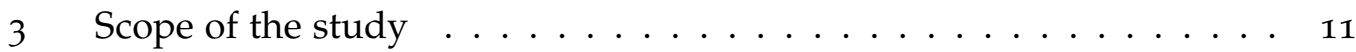

2 SURVIVAL OF SEEDLINGS WITHiN THE FIRST 6 MONTHS AFter PLANTING IN A FOREST RE-VEgETATION PROJECT IN WELLINGTON 13

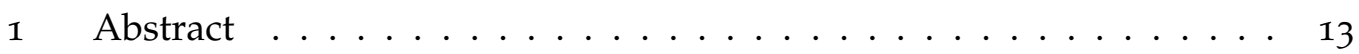

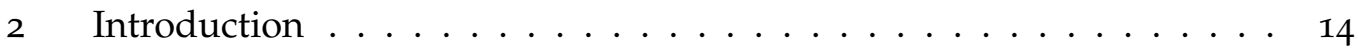

3 Material and methods .................... 16

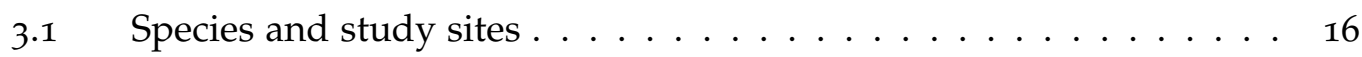

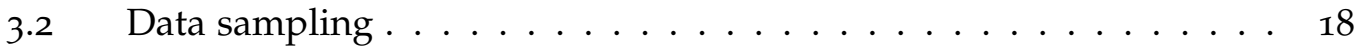

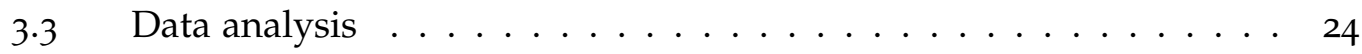

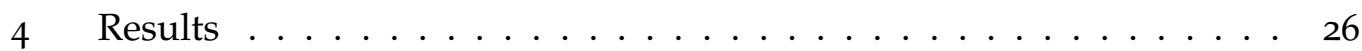

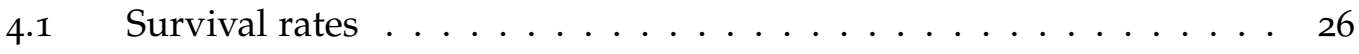

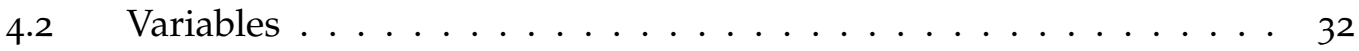

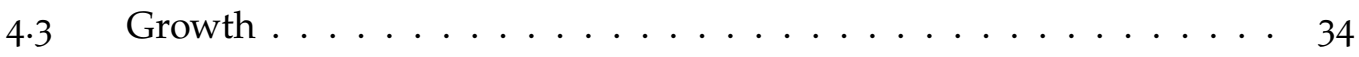

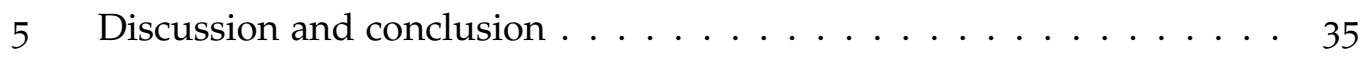


3 A COHORT ANALYSIS OF TREE SEEDLING SURVIVAL FROM I TO 4 YEARS AFTER TRANSPLANTING.

1 Abstract .............................. 41

2 Introduction ...................... 42

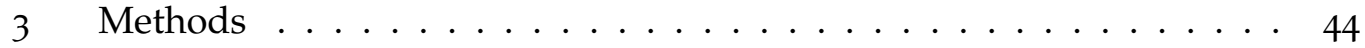

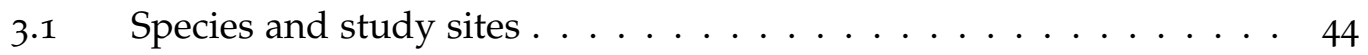

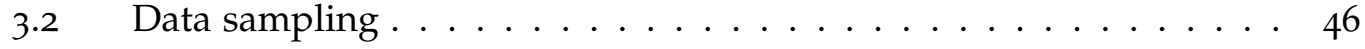

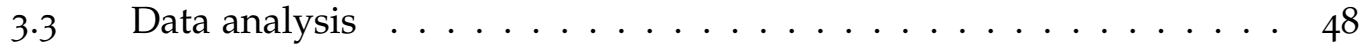

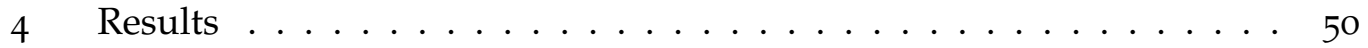

4.1 Mortality rates ........................ 50

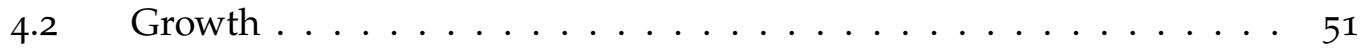

5 Discussion and conclusion . . . . . . . . . . . . 57

4 GENERAL CONCLUSIONS $\quad 63$

$\begin{array}{ll}\text { References } & 65\end{array}$

$\begin{array}{ll}\text { Appendix } 1 & 77\end{array}$

$1 \quad$ Number of seedlings transplanted in 2012 per site . . . . . . . . . . 77

2 Characteristics of the sites . . . . . . . . . . 78

3 Mortality percentages and sample size across sites . . . . . . . . . . . 79

4 Model comparison among the overall and the category models . . . . 80

5 Correlation coefficients of highly correlated fixed effects from mortality models of the 2012 seedlings . . . . . . . . . . . . . 81

$\begin{array}{ll}\text { Appendix } 2 & 83\end{array}$

$1 \quad$ Number of monitored seedlings transplanted between 2008 and 2011

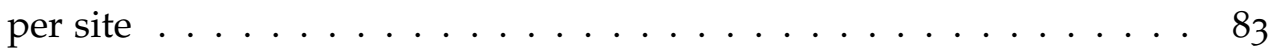

2 Characteristics of the sites transplanted between 2008 and 2011 . . . 84

3 Correlation coefficients of the fixed effects of seedlings transplanted between 2009 and $2011 \ldots \ldots$. . . . . . . . . . . . . . 85 
Figure $1 \quad$ Pre-colonization and current distribution of ecosystems in

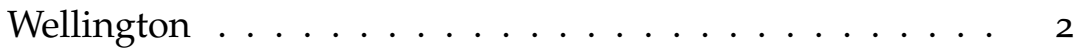

Figure 2 Location of the 2012 planting sites $\ldots \ldots \ldots 18$

Figure 3 Probability of mortality versus canopy cover, total rainfall received and $\mathrm{P}$ content in soil of wineberry and cabbage tree seedlings. . . . . . . . . . . . . . 31

Figure $4 \quad$ Grass abundance around seedlings over 6 months after planting . . . . . . . . . . . . 32

Figure 5 Differences in soil conditions between sites executed by WCC and CGs . . . . . . . . . . . . . . . 33

Figure 6 Growth of wineberry, cabbage tree and lemonwood six months after transplanting . . . . . . . . . . 34

Figure $7 \quad$ Six month period crown area difference of wineberry and lemonwood seedlings transplanted in 2012. . . . . . . . 35

Figure $8 \quad$ Location of the $2008 / 1$ 1 planting sites . . . . . . . . 45

Figure 9 Probability of mortality versus crown area and height, on day $\mathrm{o}$, of wineberry and cabbage trees transplanted between 2009 and $2011 \ldots \ldots \ldots$. . . . . . . . . 54

Figure 10 Growth of wineberry, cabbage tree and lemonwood seedlings transplanted between 2008 and 2011. . . . . . 55

Figure 11 Cubic smoothing splines of the height, measured on day 0 , and height growth 6 months after of wineberry, cabbage tree and lemonwood transplanted between 2008 and $2011 . \quad 56$ 
Table 1 Variables involved in the mortality of seedlings, supporting references, measurement methods, frequency of measurement and scale unit of each variable. . . . . . . 23

Table 2 Categories used to group grass abundance around each seedling . . . . . . . . . . . . . . 24

Table 3 Mortality numbers, six months after planting, per species and causes of mortality . . . . . . . . . . 27

Table $4 \quad$ Overall models predicting the mortality probability of wineberry and cabbage tree and AIC increase after removing each variable from the model $\ldots \ldots \ldots$

Table 5 Factors affecting mortality of plants and the correspondent variables recorded in this study . . . . . . 47

Table 6 Mortality rates and sample size of wineberry, cabbage tree and lemonwood planted between 2008 and $2011 \ldots \ldots 2$

Table 7 Mortality causes of wineberry, cabbage tree and lemonwood seedlings planted between 2008 and 2011 . . 52

Table $8 \quad$ Overall models predicting probability of mortality of wineberry seedlings and cabbage tree seedlings, transplanted between 2009 and 2011, and AIC increase after removing each variable from the model . . . . . . . 53 
ACRONYMS

AIC Akaike Information Criterion

CG Community Group

N Nitrogen

NA Non-applicable

P Phosphorous

WCC Wellington City Council 



\section{INTRODUCTION}

\section{BACKGROUND}

Historically, most of the North Island of New Zealand was covered by temperate podocarp-broadleaf rainforest (McGlone 1989). These forests hosted uniquely diverse ecological communities with, among others, over 50 different endemic bird species and a variety of native frogs, geckos, skinks, native bees and butterflies (Parrish 1984; McGlone 1989). The high numbers of endemic species and the lack of certain taxonomic groups, such as predatory terrestrial mammals and snakes, contributed to the unique biodiversity found in these forests (McGlone 2006).

Forests in the Wellington peninsula, prior to human arrival, were structured into three different canopies, each one dominated by distinct species (Gabites 1993). Ferns, such as nini (Blechnum chambersii) and pikopiko (Asplenium bulbiferum), and climbers, like kiekie (Freycinetia banksii) and supplejack (Rhipogonum scandens), constituted the lower-level canopy of this forest. Trees such as tawa (Beilschmiedia tawa), kohekohe (Dysoxylum spectabile), titoki (Alectryon excelsus), and kowhai (Sophora microphylla) formed the middle-level canopy. The high level canopy contained trees such as the northern rata (Metrosideros robusta), rimu (Dacrydium cupressinum), matai (Prumnopitys taxifolia), kahikatea (Dacrycarpus dacrydioides) and totara (Podocarpus totara) (Gabites 1993; Boffa Miskell Ltd 1998).

Following the arrival of humans in New Zealand, forested habitats across the country, including the Wellington region, have declined. Fire, logging, and the introduction of exotic animals and exotic plants have not only modified the 
extent, but also the structure and components of podocarp-broadleaf forests in New Zealand (Atkinson \& Cameron 1993; Towns et al. 1997). Prior to human arrival, broadleaf-podocarp forest covered $90 \%$ of the Wellington peninsula (Wellington City Council 2007). Currently, remnant native forest patches are restricted to less than $5 \%$ of the Wellington peninsula (Figure 1) (Wellington City Council 2007). Concurrent with this decline, fauna and flora found in the forest has been declining or has become locally extinct in the Wellington Peninsula (Towns et al. 1997; Boffa Miskell Ltd 1998; Sawyer 2004). Human occupation has also degraded the ecosystem services provided by original forest systems (e.g. water regulation, soil retention or climate regulation) (Watts \& Gibbs 2002; Stephens 2004).

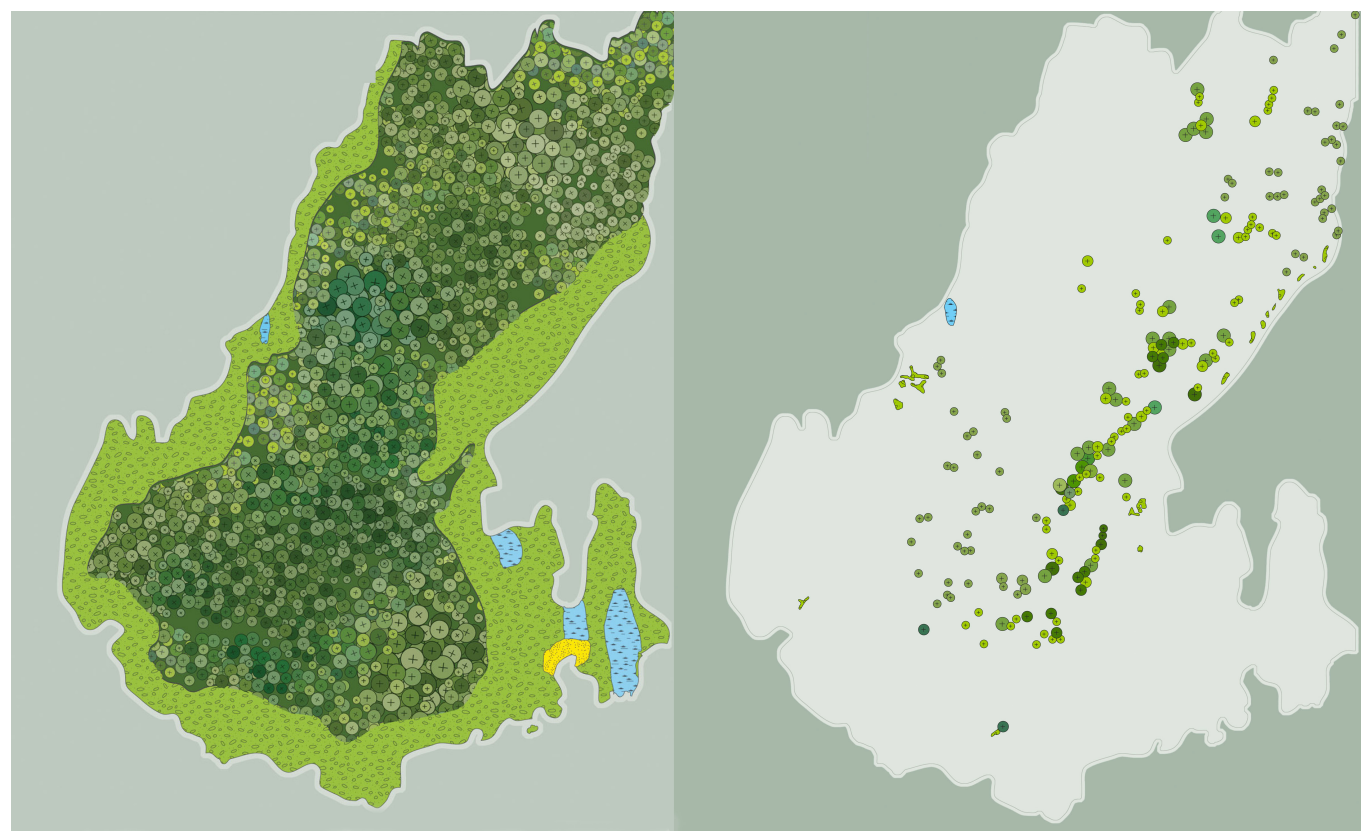

Figure 1: Ecosystems' distribution of Wellington peninsula (Lowland forest, represented in dark green, coastal forest in green, wetlands in blue and dune-lands in yellow). On the left, pre-colonization status. On the right, today's remnant patches (Wellington City Council 2007)

Although biodiversity in Wellington has become depleted, urban areas in New Zealand play an increasingly important role in the protection and restoration of the remaining flora and fauna (Sullivan et al. 2009; Meurk \& Swaffield 2000). There are currently a number of approaches used to conserve existing native forests and associated biodiversity in urban areas. One approach 
is to protect the remnant forest patches. A prime example of this approach in Wellington is Otari Wilton's bush. In 1906, the largest patch of native forest in Wellington, Otari Wilton's bush, was classified as a scenic reserve (Ministry for Culture and Heritage 2012). This status protected it from logging, farming or urban development. Given the proximity of this reserve from the city centre, inhabitants of New Zealand's capital can easily enjoy the unique features of native forest. Another conservation tool is focused on reducing the impact of introduced pests. Karori wildlife sanctuary (Zealandia) is an example of this approach. The sanctuary achieved pest mammal eradication through trapping and poisoning and its predator-proof fence is designed to prevent reinvasions (Karori Reservoir Wildlife Sanctuary Trust 2008). Zealandia has also implemented another conservation technique commonly utilised in New Zealand to restore biodiversity in forested systems, namely the reintroduction of locally extinct species. Little spotted kiwi (Apteryx owenii), North Island kaka (Nestor meridionalis septentrionalis), North Island saddlebacks (Philesturnus carunculatus rufusater) and tuatara (Sphenodon punctatus) have all been successfully translocated into Zealandia (Small 2004; Miskelly et al. 2005; Karori Reservoir Wildlife Sanctuary Trust 2008). My research focuses on another technique used to restore native biodiversity in Wellington, the re-vegetation of land with native plant species.

\section{FOREST RE-VEGETATION PROJECTS IN WELLINGTON CITY}

Forest re-vegetation projects in Wellington city typically consists of a public agency or a community group working to re-establish native vegetation cover in a given site. The goals of these projects differ and depend on both site-specific characteristics and preferences of groups carrying out the re-vegetation. Some re-vegetation projects aim to establish a vegetation cover similar to pre-European conditions, others aim to preserve the remaining native flora. Some projects aim to re-establish vegetation to help conserve endemic 
birds or to improve the physical environment of the area (e.g. soil retention or water regulation).

The restoration of native forest in Wellington city generates a number of social and ecological benefits. For example, such restoration projects contribute to conservation of native plants and animals, conservation and restoration of water and soil quality, and connect otherwise disjunct protected areas (Atkinson 1994; Meurk \& Swaffield 2000). In addition to with providing aesthetic and amenity facilities, they also enhance the cultural identity of New Zealand and increase environmental awareness (Davis \& Meurk 2001). Furthermore, restoration projects led by community groups improve the social skills and psychological well-being aspects of the volunteers, build community relationships and increase surrounding property values (Buchan 2007; Trotman 2008).

Over the past few decades, due to environmental awareness and the other benefits that restoring native vegetation provides, Wellington city has increasingly supported efforts towards the restoration of indigenous vegetation. A clear example of this re-vegetation development is the increasing number of forest re-vegetation projects undertaken by Wellington City Council and community groups of Wellington city (henceforth WCC and CG respectively) (Wellington City Council 2007). In the last 20 years, these projects have contributed to the forest restoration of Wellington city by transplanting approximately 40,000 native seedlings annually (Oliver-Smith 2012).

WCC and CGs adopted a management strategy based on an expansive literature of best techniques and guidelines for forest re-vegetation (e.g. Atkinson 1994; QEII National Trust 1997; Ledgard \& Henley 2009). The successional approach, widely used within New Zealand, can be divided into two stages. First, forest pioneer species, such as wineberry (Aristotelia serrata), lemonwood (Pittosporum eugenioides) or cabbage tree (Cordyline australis), are predominantly transplanted on sites that lack significant native vegetation. The fast growing properties and high resilience of these species allows them to 
quickly achieve a native vegetation cover. Sites that achieve an $80 \%$ native canopy cover are categorised as "free to grow" (P A Handford \& Associates Ltd 2009). In this second stage, the canopy cover provides the appropriate conditions to successfully transplant long term "climax" species, or secondary species. Secondary species often include species such as rimu, totara or tawa.

In the following paragraphs, I will describe the re-vegetation management of WCC and CGs in four chronological stages: site selection, tasks undertaken one or two years prior to the planting, the planting and the site maintenance.

- Site selection

The criteria to select forest re-vegetation sites vary between WCC and CGs. WCC selects the sites based on site characteristics. Some sites are selected because of the predominance of exotic forest species in their vegetation cover; other sites are close to key native ecosystems (such as Zealandia or Otari Wilton's bush). Forest re-vegetation projects led by WCC can also form part of landfill restoration, while other patches (such as roadsides and waste grounds) are selected for recreational purposes or aesthetic values. CGs generally select sites based on the proximity of the site to the members of specific CGs. At this stage, the CG may report the site location and a restoration plan to the WCC biodiversity department to receive support from WCC. The WCC supports CGs by purchasing and delivering the seedlings, loaning equipment and providing technical support.

- Site preparation

The site preparation stage is considered to be a crucial stage for the success of the re-vegetation project (e.g. Atkinson 1994). At this stage, the WCC and most of the CGs mow and eliminate weeds from the transplanting area. If the site characteristics are suitable, soil tilling is undertaken. WCC biodiversity staff is responsible for generating a list of the suitable species for every site. Suitability assessments are based on 
information about both the historic and current vegetation in the area. Seedlings are grown in a $\mathrm{PB}_{3}$ container well in advance of the actual transplanting process. $\mathrm{PB}_{3}$ containers are plastic bags containing $1700 \mathrm{~cm}^{3}$ of soil mix that allows the plants to grow approximately $30-60 \mathrm{~cm}$ tall.

- Transplanting of seedlings

At the time of transplanting, seedlings are between 1 and 2 years old. In order to reduce stress associated with summer droughts, planting mainly occurs in late autumn and winter. WCC staff tend to transplant large numbers of seedling in a few large operations, while CGs, restricted by their limited numbers of volunteers, tend to transplant smaller numbers of seedlings over a longer period of time. For this reason, CGs can expand the planting season until October or even the entire year. An experienced WCC staff member in forest re-vegetation allocates the seedlings according to their environmental preferences to specific sites. The majority of CGs also aim to match plants to sites with suitable characteristics. Plant densities vary, normally more than one plant per $\mathrm{m}^{2}$, but never exceeding two plants per $\mathrm{m}^{2}$. Some CGs use fertilisers, mulch, plant shields, weed mats or water the seedlings before planting. The WCC only mulches those sites where accessibility and slope allow for it.

- Site maintenance

Site maintenance differs between CGs and the WCC. WCC employees inspect and collect data on the planting development 1 week and 3-4 months after planting. Based on this information, WCC biodiversity coordinators prioritise maintenance tasks such as grass and weed control, or further in-planting. CG site maintenance is less systematic. While some groups have monthly meet-ups to control grass, weeds or pest mammals, others do not meet until the next planting season. However, there is an increasing awareness within CGs about the improvements in revegetation success associated with regular maintenance tasks. 
Re-vegetation projects in urban areas are likely to face specific challenges that can affect their success. For example, compacted urban soils, isolation, competition with other plants and introduced mammals have all been identified as important variables influencing the re-vegetation projects in urban centres including Auckland, Christchurch and Hamilton (Stewart et al. 2004; Sullivan et al. 2009; Overdyck \& Clarkson 2012). Based on previous studies, I identified the following biotic and abiotic variables as potentially important determinants influencing the success of re-vegetation projects in Wellington.

\subsection{Biotic variables}

Plants have developed distinct mechanisms for adapting to particular environments (Wardle 1985; Vallet et al. 2010) and re-vegetation projects transplanting species adapted to local conditions achieve higher survival rates (Atkinson 1994; Pezeshki et al. 2007). Thus, Wellington City Council (2007) and Greater Wellington Regional Council (2010) promote the use of local native species in re-vegetation projects. The quality of individual seedlings further influence seedling establishment. For example, the required time to overcome stress after transplanting increases with seedling height (Watson 2005).

Animals and other plants may also affect the probability of seedlings becoming established, both positively and negatively. On the one hand, the presence of certain plants, known as nurse plants, facilitate plant establishment (Camara 2011). For example, manuka (Leptosperum scoparium) is used across New Zealand in re-vegetation projects as a nurse plant (QEII National Trust 1997). On the other hand, weeds and grasses are detrimental to the growth and establishment of native seedlings (Sullivan et al. 2009; Smaill et al. 2011). Finally, the negative effects of browsing and grazing of introduced animals on seedling establishment are well documented (Husheer et al. 2006; Wilson et al. 2006; Bee et al. 2007; Camara 2011). 
Some positive and negative effects of biotic factors can be mitigated by management. For example, weeding, soil fertilizing, soil tilling, plant layout or different transplanting techniques have all been used to reduce mortality rates in re-vegetation projects (Atkinson 1994; Ferm et al. 1994; Page \& Bork 2005; Struve 2009; Sullivan et al. 2009; Smaill et al. 2011). Other potential variables cannot be controlled. These include backyards acting as propagules of exotic weeds or seedling damage from recreational activities (such as tramping, mountain biking, etc.) (Atkinson 1994; QEII National Trust 1997).

\subsection{Abiotic variables}

The physical and chemical properties of the soil affect the growth and establishment of native seedlings. For example, soil nutrients and soil compaction are known to influence the stress balance of native seedlings (Johnson 1976; Sullivan et al. 2009). Such stress can lead to growth restrictions and in some cases seedling mortality (Holzwarth et al. 2013). Wellington city soils are mainly constituted by Porirua silt loams (Wellington City Council 2004). The ranges of its physical conditions and P content were previously cited as poor (Wellington City Council 2004). Additionally, fertility, ponding risk and soil compaction of New Zealand urban soils are particularly variable, often within distances of less than 15 meters (Sullivan et al. 2009). Based on this high variability and the limited number of prime soils in Wellington city (Greater Wellington Regional Council 2012), Wellington city forest re-vegetation sites are unlikely to consistenly experience the optimal soil conditions for native vegetation described by Sorensen (2010).

Altitude, slope and aspect also influence the success of re-vegetation projects. Their influence manifests in hours of sunlight, soil stability, temperature, wind and salt exposure, and water availability (Porteous 1993; Bochet \& García-Fayos 2004). For instance, in Wellington city, north-facing slopes endure harsh 
conditions for the establishment of native species because of the limitations in soil moisture (Wellington City Council 2004).

Although native species are adapted to the local climate (Wardle 1985), the fragility of seedlings and occasional extreme weather events such as droughts may hinder the establishment of seedlings (Watson 1996). Furthermore, wind gusts have a great impact on the vegetation patterns of Wellington (Boffa Miskell Ltd 2003). This is because New Zealand's capital experiences the highest average wind-speeds in the country (Wellington City Council 2004). Therefore, random weather events may also affect the survival rates in Wellington city forest revegetation projects.

\subsection{Survival rates}

Given the significant expenditures allocated to re-vegetation projects, achieving high seedling survival may be necessary to justify these costs. The budget of WCC covers transplanting costs of approximately 40,000 plants per year for forest re-vegetation projects (Oliver-Smith 2012). The costs of producing a native seedling can vary between $\$_{1}$ to $\$ 12$, depending on the species and the time necessary to ready seedlings for transplantation. Expenses, other than the seedling production costs, typically include site preparation, planting and maintenance labour (if applicable), transportation and equipment. Therefore, maximising survival rates of the transplanted seedlings will allow WCC and CG to reduce maintenance costs and the number of seedlings required to successfully re-vegetate a site. Achieving higher survival rates also reduces the required time for a site to achieve the "free to grow" status (P A Handford \& Associates Ltd 2009). Furthermore, successful re-vegetation projects may result in community group members becoming more involved in restoration projects (Ritchie 2002). Finally, plant establishment is a key step in the conservation and enhancement of the ecosystem, culture, society, aesthetics and hydrological functions of New Zealand (Meurk \& Swaffield 200o) . 
In order to evaluate WCC planting management, P A Handford \& Associates Ltd (2009) reviewed 34 WCC forest re-vegetation sites planted between 1997 and 2008. On the one hand, P A Handford \& Associates Ltd (2009) reported that in $20091 / 3$ of the sites experienced $60 \%$ or lower levels of survival, and that 7 of the 34 sites inspected presented $80 \%$ or higher levels of survival. Successful re-vegetation projects have been defined as projects achieving at least $80 \%$ of seedling survival two years after planting (Graham \& Filmer 2007; Allen \& Kilvington 2009). Thus, based on the study executed by P A Handford \& Associates Ltd (2009), most of the forest re-vegetation projects led by WCC are classified as unsuccessful. On the other hand, there is a lack of assessment on the planting success of re-vegetation projects managed by CGs. However, based on conversations with CG coordinators, CG forest re-vegetation projects seem to present similar survival rates to those from WCC.

In order to appropriately interpret these survival rates, there are two factors to be considered. First, the survival rates obtained in the audit for WCC forest re-vegetation were visually assessed and as P A Handford \& Associates Ltd (2009) stated: "It was often difficult to be confident about the level of survival". These difficulties were due to measurement errors of the visual assessment process and the uncertainty of determining whether the plants alive at a particular site survived from the initial planting or if they were planted in following years (Porteous 1993; P A Handford \& Associates Ltd 2009). Therefore, P A Handford \& Associates Ltd's audit data may provide an inaccurate measure of the actual success of forest re-vegetation projects in Wellington. The second factor is the resilience of different species used in re-vegetation projects. In other words, different species under the same conditions suffer different levels of transplanting stress (Pratt 1999; Smaill et al. 2011). This premise calls into question any survival rate comparisons between re-vegetation sites with different species composition. Thus, in order to assess the current forest re-vegetation management it is necessary to deploy a more accurate method of assessing survival rates. 
The overall objective of my study was to identify variables affecting mortality of seedlings transplanted within forest re-vegetation projects in Wellington. In Chapter 2, I will present a study aimed at identifying the most influential variables in seedling mortality within the first 6 months after transplanting. In Chapter 3, I will analyse how the effect of variables associated with high seedling mortality change over time. These Chapters are independently designed so they can be published based on additional data. Data will be sampled until 12 months after the initial measurement, the time period commonly used to assess seedling survival in re-vegetation projects (e.g. Tyler et al. 2008; Haan et al. 2011). I will use the results presented in Chapter 2 and 3 to describe management practices that maximise seedling survival. To further improve cost-benefits of transplantation techniques I will also identify the appropriate timing to undertake transplanting. These re-vegetation guidelines will facilitate WCC and CGs achieving a cost- and labour-efficient approach to forest re-vegetation. 

SURVIVAL OF SEEDLINGS WITHIN THE FIRST 6 MONTHS

AFTER PLANTING IN A FOREST RE-VEGETATION PROJECT

IN WELLINGTON

1 ABSTRACT

There is a lack of literature that addresses methods for improving survival rates of forest re-vegetation projects in urban areas of New Zealand during the initial year after planting. In this research, I identify the survival rates of wineberry (Aristotelia serrata), cabbage tree (Cordyline australis) and lemonwood (Pittosporum eugenioides) seedlings six months after planting. I investigated 707 seedlings within ten forest re-vegetation sites in Wellington City, New Zealand. Using mixed effects models for each species, I analysed the relative importance of a number of environmental variables involved in the mortality of seedlings. Six months after planting, $9.9 \%$ of wineberry, $4.1 \%$ of cabbage tree and $1.2 \%$ of lemonwood seedlings died. Correlates of mortality in lemonwood were not analysed due to low mortality. The total amount of rainfall, presence of mulch and grass height were the most crucial variables involved in the mortality of wineberry and cabbage tree, according to their mortality prediction models. In order to maximise the survival rates of wineberry and cabbage tree seedlings within the first six months after planting, planters should focus on mitigating the effects of grass competition and increasing water availability. The models predicting mortality of both species also included other variables (e.g. soil conditions of the site or canopy cover overhead the seedling). Additional information about the influence of environmental variables over time, as well as 
in other species, may assist forest restoration projects to achieve more cost- and labour-efficient re-vegetation management.

\section{INTRODUCTION}

Native forest vegetation in New Zealand urban areas is threatened by anthropogenic disturbances associated with development, changes to the environment (e.g. soil conditions, temperature and runoff) and introduction of non-native species (Alvey 2006; Muratet et al. 2007; Hamberg et al. 2009; Trammell et al. 2011). Consequently, in the last few decades, numerous city and regional councils have developed biodiversity plans aimed at restoring native forests (Konijnendijk 2008; Sullivan et al. 2009). Transplanting native seedlings is a restoration tool widely used in urban areas to achieve forest restoration targets.

Forest restoration generates numerous ecological and social benefits. In urban areas of New Zealand, the main goal of most restoration projects is to establish a broadleaf-podocarp forest with a dense canopy cover, formed by native species, to suppress growth of unwanted non-native species. Transplanting native seedlings accelerates the natural processes of achieving this goal (Porteous 1993). The process of germination in a controlled environment avoids the initial high mortality rates associated with other techniques, such as direct seeding (Porteous 1993). Furthermore, if the planting is carried out by a local community group, transplanting native seedlings enhances the community relationships to the area and the skills and psychological well-being of the volunteers (Trotman 2008).

There are some obstacles associated with transplanting seedlings. For example, when compared to established plants, transplanted seedlings experience more perturbations in the morphology of roots and a reduced functionality of their root system (Douglas et al. 2007). It is also more labour intensive in comparison with direct seeding or assisting natural regeneration 
(Porteous 1993). In New Zealand, transplanting native seedlings is also more expensive than direct seeding (Douglas et al. 2007). Another inevitable drawback of this technique is the transplanting shock the seedlings experience. The transplanting shock can be viewed as an adaptation period to the new environment (Rietveld 1989). During this period, seedlings suffer from stress and are more vulnerable to external factors, potentially resulting in high mortality rates (Struve 2009).

Forest re-vegetation projects in Wellington are led by Wellington City Council (WCC) and local community groups (CG). Although the re-vegetation approach among sites is similar, differences exist particularly with respect to site management including the use of fertilizers, mulch, plant shields and weed mats. Independent of who executes transplantations, site preparations include mowing grass and ensuring that on the planting day no weeds are present. To minimise stress associated with summer droughts, transplanting season occurs between May to September. However, some local community groups transplant seedlings all year. WCC and CGs plant approximately 40,0oo native seedlings annually.

Due to high costs associated with re-vegetation projects (Chapter 1), maximising survival rates is a desirable goal. Restoration managers implement "best bet" re-vegetation techniques from a range of relevant literature to maximise survival rates (e.g. Porteous 1993; Atkinson 1994; Davis \& Meurk 2001). Achieving high survival rates is crucial during the first months after planting (Porteous 1993; Tyler et al. 2008; Ledgard \& Henley 2009). However, mortality rates and the appropriate techniques of current forest re-vegetation projects in New Zealand urban areas are still unclear (Phillips 2005; Sullivan et al. 2009). In Wellington City, P A Handford \& Associates Ltd (2009) assessed the survival rates of several forest re-vegetation sites and concluded that current re-vegetation projects in this area experience lower survival rates of seedlings than expected. However, given that survival estimates were pooled for different species as well as assessed visually, call into question the accuracy 
of these results (Chapter 1 ). Thus, there is a need to establish a more accurate protocol for assessing survival rates and the variables involved in the mortality of seedlings of current forest re-vegetation management in urban areas.

In this Chapter, I aim to assess the survival rates of tree seedlings in urban forest re-vegetation projects of $\mathrm{New}$ Zealand and determine the relative importance of the factors involved in the mortality of seedlings transplanted in local restoration projects. The outcomes of this study will allow agencies, managing forest re-vegetation projects, to adapt their re-vegetation management to achieve the highest feasible survival rates.

\section{MATERIAL AND METHODS}

\subsection{Species and study sites}

Of the 56 plant species commonly used in re-vegetation projects in Wellington, I chose to investigate the seedling survivorship of the following three species: Aristotelia serrata, Cordyline australis and Pittosporum eugenioides. These species are among the fastest growing native species in New Zealand (Busell 1968; Marden et al. 2005), making these species commonly transplanted pioneer species within the Wellington City forest re-vegetation projects (Mitcalfe 2002).

Aristotelia serrata also known as wineberry or makomako, grows up to 8 meters in height (Poole \& Adams 1994). The root system of this broadleaf species is known as a heart-rooted system (Marden et al. 2005) where roots rise from or near the root bole and gradually replace the taproot (Phillips \& Watson 1994).

Cordyline australis, also known as cabbage tree or ti kouka, grows up to 20 meters in height (Harris et al. 2003). Cabbage trees are monocotyledons with narrow and linear leaves clustered into clumps (Harris 2002). Cabbage trees develop branched central tuberous rhizomes, which give rise to planes of lateral roots (Marden et al. 2005). 
The third species is Pittosporum eugenioides, also referred to as lemonwood or tarata, can reach a height of 13 metres. This species, of yellowish-green petiolate leaves, presents a heart-rooted root system (Marden et al. 2005).

Wellington City, the site for this study, is situated in the southern most part of New Zealand's North Island. This area has a mild temperate climate. The city experiences an average rainfall of $127 \mathrm{~cm}, 2000$ hours of sunshine per year and significant wind gusts, greater than $60 \mathrm{~km} / \mathrm{h}$, an average of 173 days per year (NIWA 2013).

Ten forest re-vegetation sites within Wellington City were selected for this study (Figure 2). Site selection was based on whether or not the species selected for this study were among the seedlings transplanted in 2012. I initially aimed to monitor 30 seedlings of each species per site. However, due to allocation issues from the local nursery, some sites received unequal number of seedlings and species (Appendix 1.1). The size of the sites varied from 1 to 10 ha. Prior to restoration, these areas were previously used for landfills, roadsides or waste land in suburban areas (Appendix 1.2).

Berhampore nursery in Wellington City grew all the seedlings for the respective re-vegetation projects in $\mathrm{PB}_{3}$ containers (Chapter 1). Seedling transplanting techniques were similar across all sites. One week prior to the transplanting day, re-vegetation practitioners mowed the grass in each site. In order to provide seedlings enough time to acclimatise before the summer drought period, Wellington City Council (WCC) and local community groups (CG) transplanted the seedlings between May and September of 2012 (Appendix 1.2). Although plant density varied, it never exceeded two plants per square metre. 


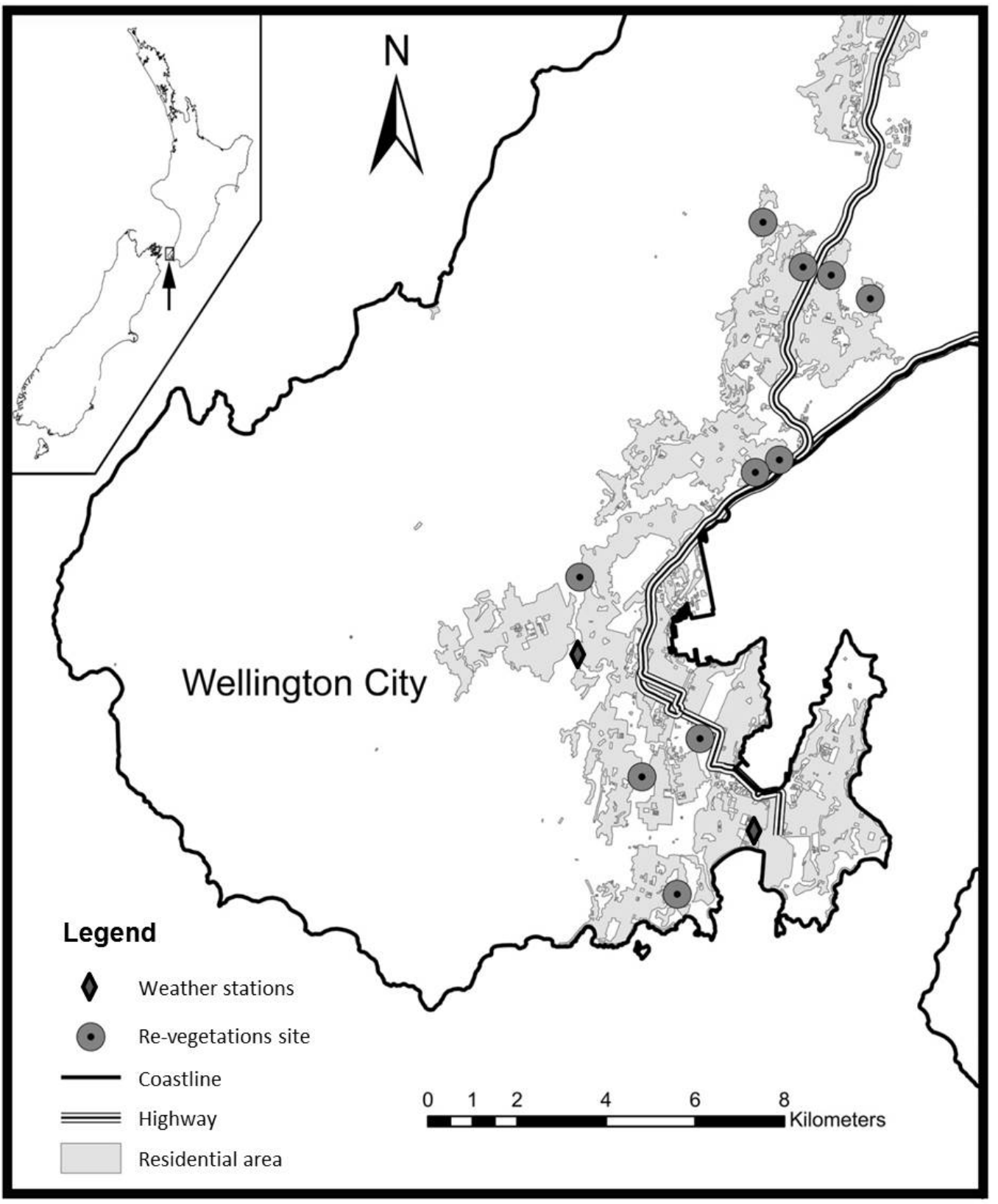

Figure 2: Location of the 10 re-vegetation sites planted in 2012.

\subsection{Data sampling}

Data were collected from May 2012 until March 2013. On the transplanting day, each seedling was individually marked with an aluminium identification tag and its location was recorded on a map of the re-vegetation site. To avoid biasing data (e.g. differences in the transplanting techniques), seedlings were 
randomly selected and marked after they were transplanted. Seedling survival was assessed 2 weeks, 2 months, 4 months and 6 months after the transplanting date. Seedlings that could not be relocated during site investigations were considered dead. The cause of death was recorded for each dead seedling ("standing", "uprooting" or "mowed").

The growth of the seedlings 6 months after the transplanting date was measured by the difference in seedlings height and trunk diameter or crown area. Seedling height was measured between the ground and the highest green leaf of the seedling. Trunk diameter was also factored in the growth assessment of cabbage tree seedlings. Trunk diameter of wineberry and lemonwood trees could not be assessed since some of the species presented multiple trunks. In order to assess the growth of wineberry and lemonwood seedlings, I measured the longest width of the crown (crown maximum width) and its perpendicular distance of the crown (crown perpendicular width). Negative height and crown width differences were due to leave loss and/or branch damaged.

To estimate the most important variable or variables involved in the mortality of seedlings, I recorded: size of the transplanted seedlings, surrounding physical environment of each seedling, relationships with other organisms, soil conditions and management differences (Table 1). Variables were chosen based on previous studies (Table 1) that proved the direct or indirect influence these independent variables had on seedling mortality.

\section{- Seedling size}

Height of the seedling on the transplanting day was measured using a measurement tape. Trunk diameter, on the transplanting day, was measured only for cabbage trees. The longest width of the crown and the perpendicular crown distance were recorded for individuals of wineberry and lemonwood. Additionally, plants suffering damage to branches caused by high winds or human disturbances were considered to have "mechanical damage." 


\section{- Physical site conditions}

Weather, exposure to sunlight and topography of the site were recorded to determine physical conditions at the transplanting site. The quantity of rainfall each site received was based on the total amount of rainfall received in two weather stations ("Kelburn" and "Airport", see Figure 2) located in Wellington City during the 6 months following each planting event (Appendix 1.2). The rainfall information was retrieved from NIWA (2013). The amount of canopy cover overhead each seedling was measured using a densiometer, a curved mirror device divided into 24 squares that allows for cover estimations by counting the number of shaded squares by neighbouring vegetation. Holding the device directly above the seedling, I estimated canopy cover facing all general directions: north, south, west, and east. A clinometer and a compass were used to measure the slope and aspect of each seedling, respectively.

\section{- Ecological relationships}

I determined the relative importance of other species, both plants and animals, on the survival of the seedlings by measuring the abundance and height of other plants and the relative abundances of potential herbivores. The abundance of grass in a quadrant $\left(1.5 \times 1.5 \mathrm{~m}^{2}\right)$ surrounding each seedling was recorded. Percentage of grass was visually estimated for each seedling and assigned into one of the six different categories of the scale explained in Table 2 (Rose \& Frampton 1999). Additionally, grass height was also visually estimated and classified as higher or lower than the plant.

Three tracking tunnels were set up per site to assess relative rodent abundances at the sites. To reduce the probability of tracking the same individual, tunnels were set up a minimum of 50 metres apart (Porteous 1993). Tracking tunnels were set up in September 2012 and March 2013 to record rodents presence at both annual peaks (minimum and maximum) of their population (Ogden \& Gilbert 2009). To measure rabbit levels, the 
sites were given a value of the Modified McLean Scale. The Modified McLean Scale contains seven levels, which are based on the number of rabbits and rabbit signs seen in the area (National Pest Control Agencies 2012). I did not estimate the abundance of possums because, due to the poison intense control efforts of Greater Wellington Regional Council, the presence of this mammal pest in Wellington peninsula is very low (Oliver-Smith 2012).

\section{- Soil conditions}

Soil acidity, organic matter, fertility and soil compaction were measured to determine the soil conditions at each site. I measured $\mathrm{pH}$, Olsen-P and total $\mathrm{N}$ content to qualify soil acidity, soil fertility and organic matter $\mathrm{N}$ status (Hill et al. 2003). Five grams of soil, taken at $15 \mathrm{~cm}$ depth, were collected from nine randomly selected points in each site. The $\mathrm{pH}$ of these samples was measured using a $\mathrm{pH}$-meter in a 2:1 water-to-soil ratio (Blakemore et al. 1987) in the School of Geography, Environment and Earth Sciences laboratories at Victoria University of Wellington. Soil samples were sent to the Landcare Research laboratories for measuring Phosphorous and Nitrogen contents. Phosphorous content, indicated by the Olsen-P content, was obtained using the bicarbonate extraction method (Olsen 1954). N content was assessed by the dry combustion method using a Leco CNS200o Analyzer (Leco 2003). I recorded the average soil compaction by pooling values obtained at each location where soil samples were collected using a proving ring penetrometer. The penetrometer was used to record the energy required $\left(\mathrm{kg} / \mathrm{cm}^{2}\right)$ to penetrate the device to a soil depth of $15 \mathrm{~cm}$.

\section{- Management}

During planting, I recorded whether or not the seedlings were mulched. Additionally, if the seedling was not firmly attached to the ground, 
MATERIAL AND METHODS

primarily due to inappropriate seedling planting or accidental breaking, it was labelled as an "unstable plant." 
Table 1: Variables involved in the mortality of seedlings, supporting references, measurement methods, frequency of measurement and scale unit of each variable.

\begin{tabular}{|c|c|c|c|c|c|}
\hline Category & Attribute & Reference & Measurement method (unit) & $\begin{array}{c}\text { Timing of } \\
\text { measurement }\end{array}$ & $\begin{array}{c}\text { Scale of } \\
\text { sample unit }\end{array}$ \\
\hline \multirow{4}{*}{$\begin{array}{l}\text { Seedling size and } \\
\text { damage }\end{array}$} & Initial seedling height & Davis (2009) & Height of the highest green leave (mm) & 1 & Individual \\
\hline & Initial trunk diameter & Davis (2009) & Trunk diameter at the base $(\mathrm{mm})$ & 1 & Individual \\
\hline & Initial seedling's canopy cover & Davis (2009) & Length and width of the canopy cover (mm) & 1 & Individual \\
\hline & Mechanical damage & Porteous (1993) & Visual (Presence/absence) & 2 & Individual \\
\hline \multirow{4}{*}{ Physical environment } & Rainfall & Porteous (1993) & Extracted from NIWA (mm) & 3 & Regional \\
\hline & Slope & Bochet \& García-Fayos (2004) & Clinometer (Degrees) & 1 & Individual \\
\hline & Aspect & Bochet \& García-Fayos (2004) & Compass (Degrees) & 1 & Individual \\
\hline & $\begin{array}{l}\text { Canopy cover } \\
\text { (overhead the seedling) }\end{array}$ & Lhotka \& Loewenstein (2008) & Densiometer $(\%)$ & 1 & Individual \\
\hline \multirow{4}{*}{$\begin{array}{l}\text { Ecological } \\
\text { relationships }\end{array}$} & Grass abundance & Ledgard \& Henley (2009) & Visual ( 1 to 5 Scale) & 2 & Individual \\
\hline & Grass height & Ledgard \& Henley (2009) & Visual (Grass higher or lower than seedling) & 2 & Individual \\
\hline & Level of rodents & Wilson et al. (2006) & Tracking tunnels (Presence/absence) & 4 & Site \\
\hline & Level of rabbits & Camara (2011) & Modified McLean Scale ( 1 to 6 scale) & 4 & Site \\
\hline \multirow{4}{*}{ Soil conditions } & $\mathrm{pH}$ & Anastasiou \& Brooks (2003) & pH-meter (o to 14 scale) & 5 & Site \\
\hline & P content & Watt et al. (2008) & Olsen-P method $(\mathrm{mg} / \mathrm{kg})$ & 5 & Site \\
\hline & Total $\mathrm{N}$ content & Watt et al. (2008) & Dumas dry combustion method (\%) & 5 & Site \\
\hline & Soil compaction & Sullivan et al. (2009) & Proving ring penetrometer $\left(\mathrm{kg} / \mathrm{cm}^{2}\right)$ & 5 & Site \\
\hline \multirow{2}{*}{ Management } & Mulch & Arnold et al. (2005) & Visual (Presence/absence) & 1 & Individual \\
\hline & Planting date & Page \& Bork (2005) & Planting date (days) & 1 & Site \\
\hline
\end{tabular}

a $1=$ Transplanting day. 2= Transplanting day and 2 weeks, 2 months, 4 months and 6 months after. $3=$ May $2013 \cdot 4=$ September 2012 and March $2013 \cdot 5=$ February 2013. 
Table 2: Categories used to group grass abundance around each seedling (Rose \& Frampton 1999).

\begin{tabular}{cc} 
Category & Grass abundance \\
\hline 0 & $0 \%$ \\
1 & $0 \%-20 \%$ \\
2 & $20 \%-40 \%$ \\
3 & $40 \%-60 \%$ \\
4 & $60 \%-80 \%$ \\
5 & $>80 \%$
\end{tabular}

\subsection{Data analysis}

Some independent variables were modified to facilitate the analysis. The initial crown area (CA) of wineberry and lemonwood trees was calculated, assuming an elliptical shape of the canopy cover (Peek 1970), using the following equation: $\mathrm{CA}\left(\mathrm{cm}^{2}\right)=\pi \frac{(\mathrm{Cm} / 2)(\mathrm{Cp} / 2)}{100}$, where $\mathrm{Cm}$ is the maximum crown width of the seedling $(\mathrm{mm})$ and $\mathrm{Cp}$ is the perpendicular width $(\mathrm{mm})$ of the crown. I averaged the total amount of rainfall recorded in "Kelburn" and "Airport" weather stations to determine the total amount of rainfall that seedlings received during the 6 months after planting. Although precipitation in Wellington is influenced by topography and distance to the sea (Boffa Miskell Ltd 2003), by averaging records between these two weather stations, variation associated with local conditions become negligible. In order to assess if seedlings facing south have a different mortality probability, I determined northernness for each seedling. Northernness was estimated by subtracting 180 from actual compass readings for each seedling. The seedlings located in a flat area, because they were neither facing south nor north, were thus assigned a northernness value of 90. I averaged the four canopy cover measurements 
(south, west, north and east) recorded for each seedling. I also averaged the percentages of grass per seedling recorded in each investigation. Based on the proportion of tracking tunnels occupied, I calculated the relative abundance of rodents per site (Ogden \& Gilbert 2009).

Prior to data analysis, rabbit abundance was removed since there were equal values among sites (Appendix 1.2). Seedlings labelled as "unstable plants" and "mowed" were also removed from the analysis because their mortality causes were unrelated to other variables measured at the site.

Mixed effects models were used to predict the mortality probabilities of wineberry, cabbage tree and lemonwood seedlings. Several authors (e.g. Hamilton \& Edwards 1976; Buchman et al. 1983; Yao et al. 2001) used this approach to link environmental variables to observed mortality of individual plants. Due to potentially unrecorded differences between sites, I treated the variable "site" as a random effect. It was necessary to remove from these models the variables that present a weak influence in the mortality of the seedling because a high number of variables were recorded. To avoid multicollinearity, variables that presented the highest amount of high correlations $(r>0.8)$ with other variables were removed from the model (Bates 2010). This process was repeated until the highest correlation coefficient between variables was lower than 0.8 in each species mortality model.

After multicollinearity analyses, I used a stepwise backward regression approach to remove the unimportant covariates involved in the mortality of seedlings for each species models. This stepwise backward regression was based on a model fit measurement, the Akaike Information Criterion (AIC). As explained by Shtatland et al. (2001), a stepwise backward regression based on AIC improves the prediction and interpretation of this technique. After removing all the unimportant covariates, a minimum adequate mortality model (henceforth, overall model) was generated with variables that have an important influence in seedling mortality. 
I compared the differences in the model size $(\triangle \mathrm{AIC})$ before and after removing each variable from the overall model to identify the most important variables in the mortality of each species (Bates 2010). Furthermore, I considered models within a $\triangle \mathrm{AIC}$ of less than 2 units indistinguishable in their respective performances (Burnham \& Anderson 2002).

To estimate the weight of each category in the overall model, I ranked AIC weights $\left(\mathrm{w}_{\mathrm{i}}\right)$ (Burnham \& Anderson 2002). Stepwise backward regression, based on AIC values, was executed for each category model to determine whether or not the model perform better by non-including any of the proposed variables (null model).

Statistical analyses were executed using the R-Program (R Development Core Team 2012) and the LME4 package (Bates et al. 2012). To assist interpretation of results, cubic smoothing splines (Reinsch 1967) were generated. Smoothing splines are used in mixed effect models to show the trend in a binary dependent variable with respect to a certain independent variable (Bates 2010).

4 RESUlts

\subsection{Survival rates}

Eleven seedlings, nine of which were dead, were removed from the analysis because they were planted inappropriately or accidentally damaged (labelled as "Unstable plant" and "Mowed"). With the exclusion of these seedlings, 36 of the $696(5.2 \%)$ marked seedlings died within 6 months after they were planted. Seedling mortality ranged from o to $12 \%$ across the sites (Appendix 1.3). Differences also occurred at a species level (Table 3). Wineberry seedlings experienced the highest mortality (24 of 243 seedlings) while lemonwood experienced the lowest mortality ( 3 of 233 seedlings). The majority of seedlings mortality was not attributed to physical damage (Table 3). 
Table 3: Mortality numbers, six months after planting, per species and causes of mortality

\begin{tabular}{|c|c|c|c|}
\hline & Wineberry & Cabbage tree & Lemonwood \\
\hline Standing & 20 & 8 & 2 \\
\hline Uprooting & 1 & 1 & $\mathrm{o}$ \\
\hline Missing & 3 & 2 & 1 \\
\hline Mowed $^{a}$ & $\mathrm{o}$ & 2 & 1 \\
\hline Unstable plant ${ }^{a}$ & 2 & 2 & $\mathrm{o}$ \\
\hline Total mortality rates & $10.6 \%$ & $6.6 \%$ & $1.7 \%$ \\
\hline $\begin{array}{l}\text { Mortality rates of } \\
\text { analysed seedlings }\end{array}$ & $9.8 \%$ & $4.8 \%$ & $1.3 \%$ \\
\hline Total planted & 245 & 228 & 234 \\
\hline
\end{tabular}

The overall models executed in this research are species specific. Lemonwood experienced low mortality (1.3\%) and was removed from the analysis (Table 3 ). The overall models of wineberry and cabbage tree show some factors in common, but the interactions between these factors and mortality were species specific.

The physical conditions of the site and the relationship of other organisms were among the highest weighted category models in the overall model to predict mortality of wineberry and cabbage trees. However, given the weak prediction power of some of the category models, the overall model had a high probability of being selected as the best model to predict mortality of these two species (Appendix 1.4).

\subsubsection{Wineberry}

Prior to generating the overall model to predict mortality of wineberry, the planting date and $\mathrm{N}$ content were removed due to their high correlation with other variables (Appendix 1.5).

Although wineberry generally performs better under a denser canopy cover, the results showed exponential increases of mortality probabilities under dense 
canopy (Figure 3). An increase in the total amount of rainfall decreased the probability to die in this species (Figure 3). Seedlings, shorter than the surrounding grass, also experienced a higher mortality probability. This probability increased when the P content in soil increased (Table 4). While the lowest mortality probability occurs at $7 \mathrm{mg} / \mathrm{kg}$ of $\mathrm{P}$ available in the soil, the highest mortality probability occurred at approximately $18 \mathrm{mg} / \mathrm{kg}$. However, this relationship did not follow a particular pattern. The last variable that contributed in the overall model to predict the mortality of wineberry was mulch. Mulched seedlings experienced a lower mortality probability than seedlings without this treatment.

Removing from the overall model the total amount of rainfall received, the height of the grass or mulching generated the highest AIC differences (higher than 2 AIC units).

\subsubsection{Cabbage tree}

Prior to generating models predicting mortality of cabbage tree seedlings, planting date, soil compaction and $\mathrm{pH}$ were removed due to their high correlation with other variables (Appendix 1.5).

The mortality probability of cabbage tree seedlings was negatively correlated with the initial size of the trunk (Table 4). It was also negatively correlated with the canopy cover overhead the seedlings and the total amount of rainfall received. There was a linear relationship between mortality probability and the canopy cover (Figure 3). Mortality probability of the cabbage trees experienced an unusual peak in its relationship with the total amount of rainfall received (Figure 3). Cabbage tree seedlings situated in a northern facing slope experienced higher probability of death. Grass height and mulching affect cabbage trees similarly to wineberry (Table 4). Relative rodent abundance and P content increased the probability of mortality $(<2 \Delta \mathrm{AIC})$. 
Removing the total amount of rainfall received or mulching generates the highest AIC differences (higher than 2 AIC units) in the overall model of cabbage trees. 
Table 4: Overall models predicting the mortality probability of wineberry and cabbage tree and AIC increase after removing each variable from the model

\begin{tabular}{|c|c|c|c|c|c|c|c|c|c|}
\hline Species & AIC & $\log \operatorname{Lik}$ & Deviance & Variables & Estimate & Std. Error & $\mathrm{z}$ value & $\operatorname{Pr}(>|z|)$ & $\begin{array}{l}\text { Increase in model AIC } \\
\text { if the variable is removed }\end{array}$ \\
\hline \multirow{6}{*}{ Wineberry } & \multirow{6}{*}{143.1} & \multirow{6}{*}{$-64 \cdot 56$} & \multirow{6}{*}{129.1} & (Intercept) & 1.82 & 2.66 & 0.68 & 0.49 & \\
\hline & & & & Canopy cover & 0.02 & 0.01 & 1.84 & 0.07 & 1.26 \\
\hline & & & & Rainfall & -0.02 & 0.01 & -2.75 & 0.01 & $5 \cdot 52$ \\
\hline & & & & Grass height & 2.60 & 0.99 & 2.63 & 0.01 & 9.67 \\
\hline & & & & P content & 0.09 & 0.05 & 1.92 & 0.06 & 1.63 \\
\hline & & & & Mulch & -2.91 & 0.99 & -2.92 & 0.00 & 9.27 \\
\hline \multirow{9}{*}{ Cabbage tree } & \multirow{9}{*}{86.81} & \multirow{9}{*}{$-33 \cdot 4$} & \multirow{9}{*}{66.81} & (Intercept) & 13.43 & 7.00 & 1.92 & 0.06 & \\
\hline & & & & Initial trunk diameter & -0.26 & 0.16 & -1.65 & 0.10 & 0.72 \\
\hline & & & & Canopy cover & -0.06 & 0.04 & -1.47 & 0.14 & 1.58 \\
\hline & & & & Northerness & 0.02 & 0.01 & 1.84 & 0.07 & 1.69 \\
\hline & & & & Rainfall & -0.03 & 0.01 & -2.67 & 0.01 & 5.89 \\
\hline & & & & Rodents abundance & 0.04 & 0.02 & 1.83 & 0.07 & 1.77 \\
\hline & & & & Grass height & 1.82 & 0.88 & -2.06 & 0.04 & 1.86 \\
\hline & & & & P content & 0.13 & 0.09 & 1.45 & 0.15 & 0.09 \\
\hline & & & & Mulch & -2.82 & 1.50 & -1.88 & 0.06 & 2.29 \\
\hline
\end{tabular}



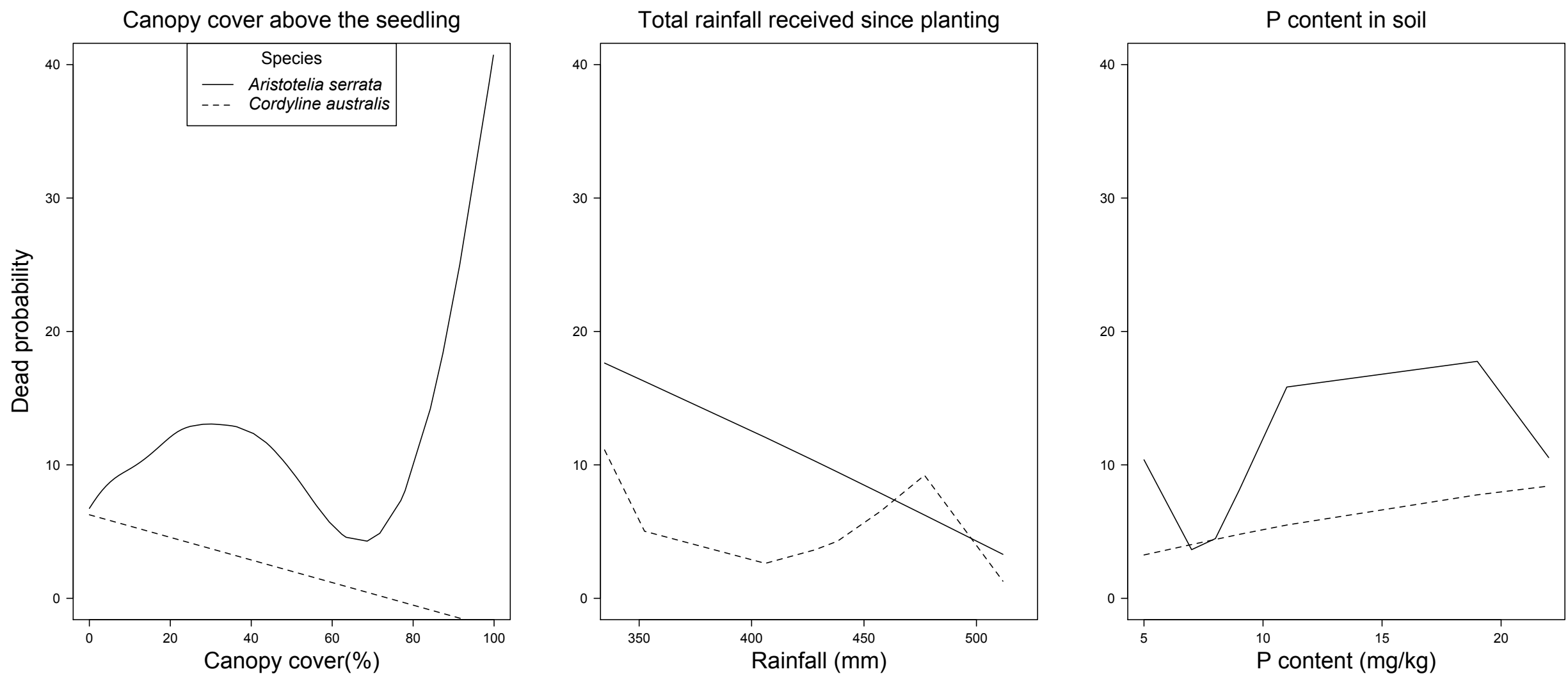

Figure 3: Cubic smoothing splines of the probability of mortality versus canopy cover, total rainfall received and P content in soil of wineberry and cabbage tree seedlings. 


\subsection{Variables}

Due to the lack of previous vegetation in a majority of the sites, more than half $(55 \%)$ of the seedlings experienced an overhead canopy cover of less than $10 \%$. Initially, $93 \%$ of the seedlings experienced a grass abundance value between 0 to $20 \%$. Grass within $1.5 \mathrm{~m}^{2}$ of the seedling increased over time after planting (Figure 4). Six months after planting occurred, $83 \%$ of the seedlings alive faced a grass abundance value between 80 to $100 \%$. The probability of grass being taller than seedlings increased over time. On the planting day, grass was taller than only $1 \%$ of the seedlings, which increased to $66 \%$ six months after the planting.

\section{Grass abundance over time}

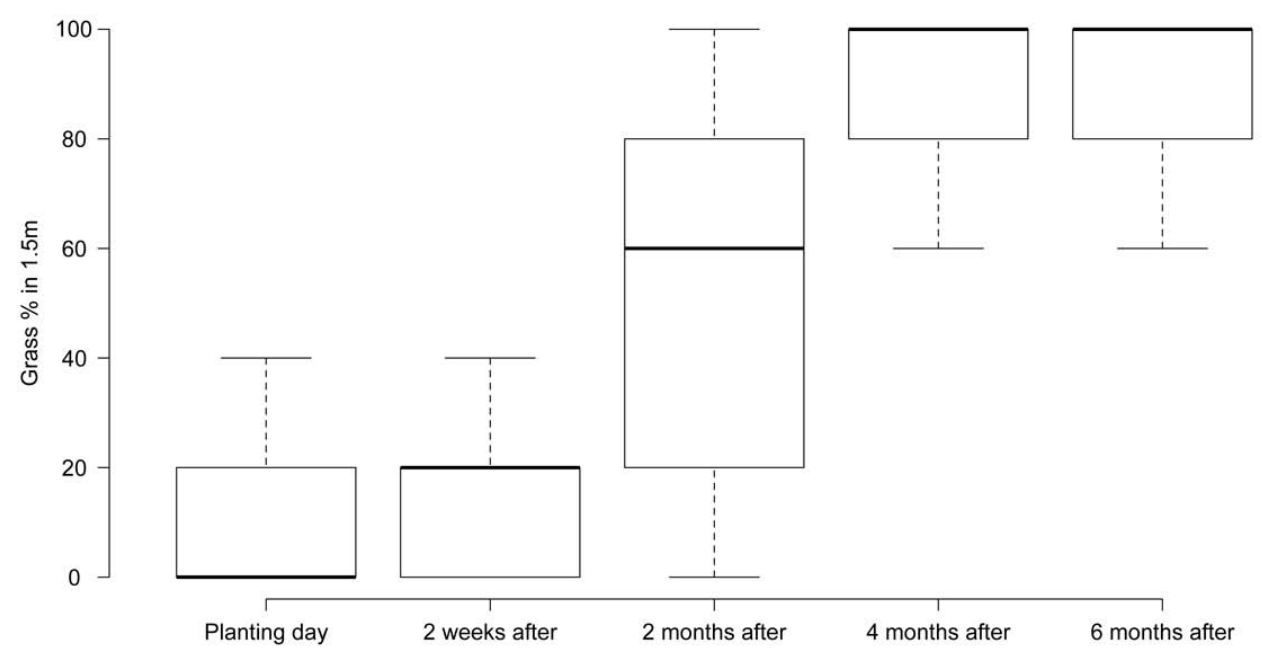

Figure 4: Grass abundance around seedlings, pooled across all the sites, over 6 months after planting.

During the monitoring period of this research, the city experienced an average temperature of $12.86^{\circ} \mathrm{C}$, a total of $678.8 \mathrm{~mm}$ of rainfall and the strongest wind gust was $129 \mathrm{~km} / \mathrm{h}$ (NIWA 2013). These values are within the average weather range that the area experienced in previous years. However, most of the rainfall received in January, February and March occurred during one event (Turner 2013). This, linked with one of the sunniest summer on record, lead to unusual drought conditions (Turner 2013). 
There were differences between the two agencies in charge of the forest re-vegetation projects in Wellington city (WCC and CG). On average, WCC planted their seedlings earlier in the year than the CGs (Appendix 1.2). WCC sites contained lower quality soil than those sites carried out by CG (Figure 5). While CGs mulched $35 \%$ of the seedlings transplanted, WCC did not mulch any of the seedlings recorded in this study. Six months after transplanting, 30 of the $448(6.7 \%)$ seedlings transplanted by WCC had died. Seedlings transplanted by CG experienced similar outcomes, with 15 of the $259(5.8 \%)$ seedlings transplanted dying over the 6 month period.

Soil acidity

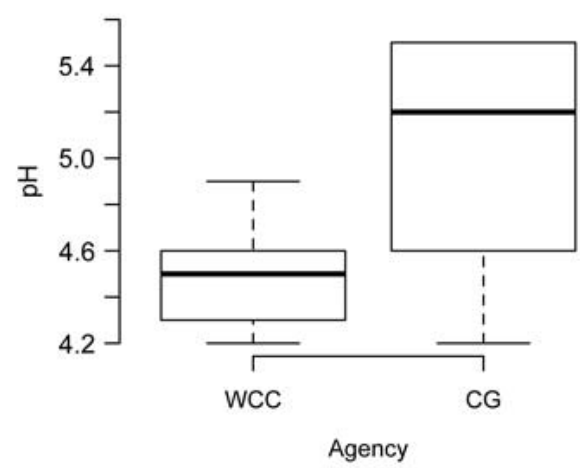

Organic matter $\mathrm{N}$ content

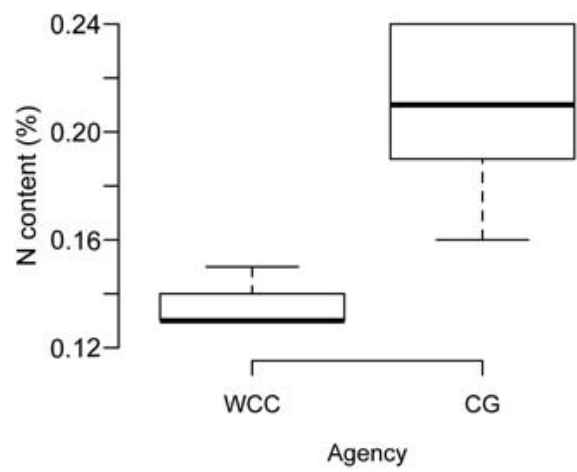

Soil fertility

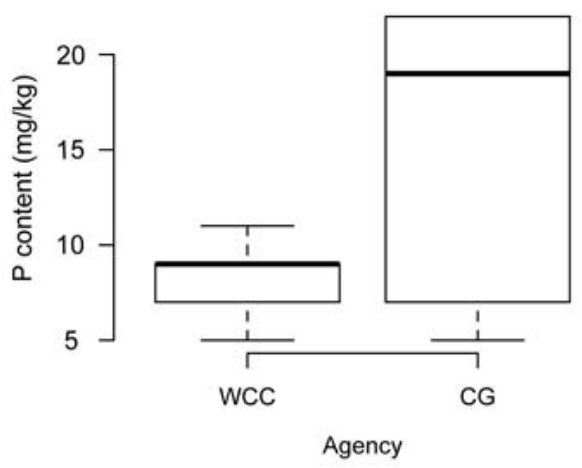

Soil compaction

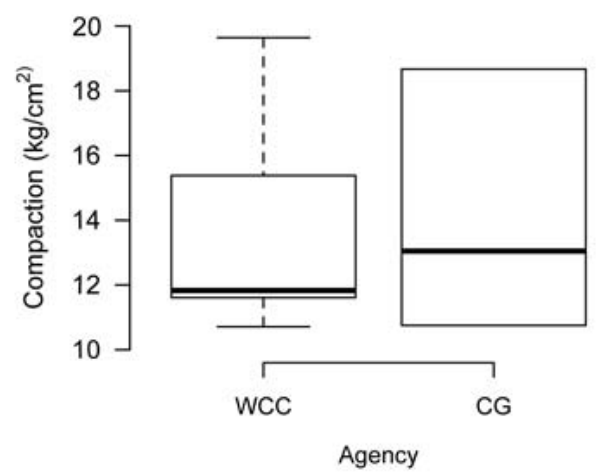

Figure 5: Differences in soil conditions ( $\mathrm{pH}, \mathrm{P}$ content, $\mathrm{N}$ content and soil compaction) between re-vegetation sites executed by WCC and CGs 
RESULTS

\section{$4 \cdot 3$ Growth}

Seedling growth was similar across all three species. Although certain wineberry seedlings experienced a higher growth than the other species, there were no differences among the average growth of species (Figure 6 and 7). The trunk growth of cabbage tree seedlings was not measurable during the first six months.

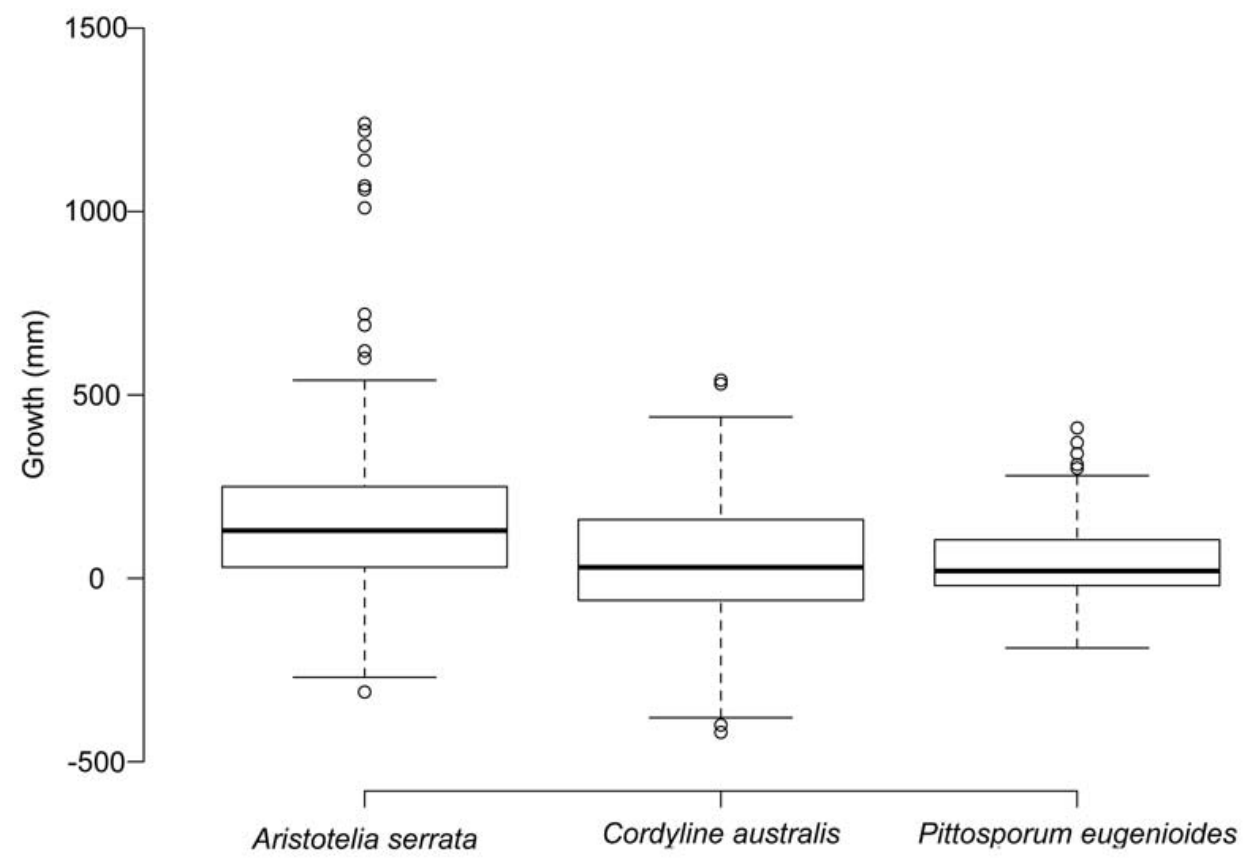

Figure 6: Growth of wineberry, cabbage tree and lemonwood six months after transplanting 
Aristotelia serrata

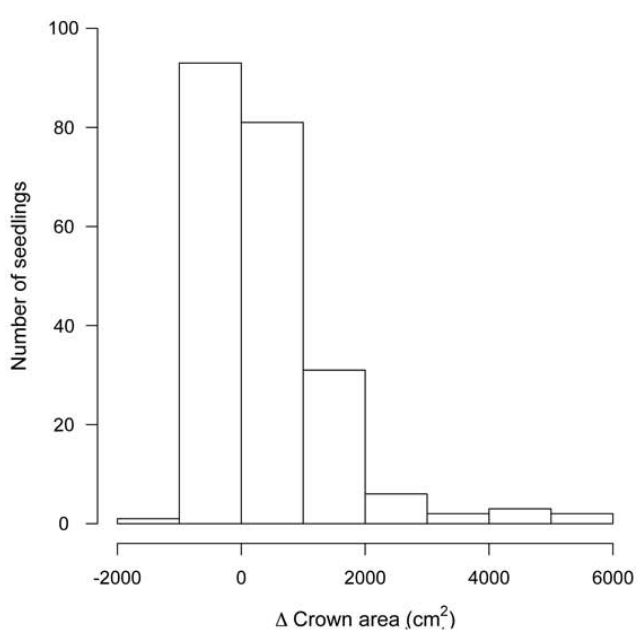

Pittosporum eugenioides

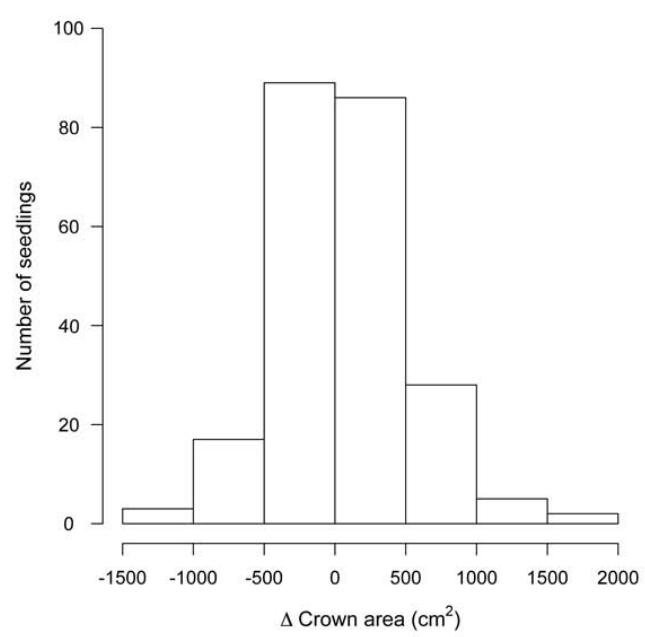

Figure 7: Six month period crown area difference of wineberry and lemonwood seedlings transplanted in 2012.

\section{DISCUSSION AND CONCLUSION}

The most influential variables causing the mortality of wineberry and cabbage trees were the total amount of rainfall a seedling received after transplanting, mulching and grass height (Table 4). However, other variables such as canopy cover and soil conditions also influenced observed mortality rates.

In comparison with the category models, the overall model had a high probability of being selected as the best model to predict mortality of wineberry and cabbage tree seedlings (Appendix 1.4). This result highlights the importance of including the effects of specific variables combined, rather than the effects of a specific category, to predict the mortality probability of a seedling.

Results showed significant relationship between total amount of rainfall received by a seedling and its probability of mortality. This result is in agreement with previous studies highlighting the availability of water as the main cause of stress and mortality in re-vegetation projects using seedlings (e.g. Watson 1996). Furthermore, these results may indicate the effects on seedling 
mortality of the unusual drought conditions occurred in the study area during January, February and March.

Results also suggested that grass competition is an important factor influencing mortality of seedlings. Grass competes with native seedlings for basic resources, such as water, nutrients and light (Porteous 1993; Sullivan et al. 2009). Results further indicated that grass height was more detrimental than grass abundance. It appears that insufficient light received by the seedlings may have caused seedling mortality. Other variables, such as the initial trunk diameter, canopy cover, and P content of soils also affected seedling mortalities.

The model to predict mortality of cabbage trees included the initial trunk diameter of the seedlings. This highlights the importance of transplanting robust seedlings. However, the remaining variables did not affect observed mortality of either wineberry or cabbage trees. Results suggest that height, crown area and damage to branches did not affect plants as notably as the size of the trunk of the seedlings.

Both species performed better under denser canopy cover. The better performance might be related to the shelter conditions that surrounding vegetation may provide to the seedlings (Parker 1995). However, probability of mortality of wineberry seedlings increased at high levels of canopy cover. High probabilities of seedling mortality may be caused by the insufficient light that seedlings received.

Given that soil conditions at re-vegetation sites in Wellington generally fell below levels considered optimal for forest re-vegetation (Sorensen 2010), soil conditions appeared to affect seedling mortalities. P content in the recorded sites varied between low and optimal values for forestry (Sorensen 2010). According to the optimal values of soil conditions provided by Sorensen (2010), it is expected that seedlings transplanted in sites with lower $\mathrm{P}$ content experience higher mortality probabilities. However, based on the mortality recorded in my study, mortality probability of wineberry and cabbage tree seedlings increased with P content. The unexpected result may be consequence 
from the better scenario, not just for the transplanted seedlings, but also for invasive species that sites with higher $\mathrm{P}$ availability may provide (Burke \& Grime 1996). Thus, seedlings transplanted in sites with higher P level in soil may suffer a higher competition with grass and weeds than seedlings transplanted in sites with lower P levels. Furthermore, the effects of soil conditions in seedling mortality could be misinterpreted because the measurement values of these parameters were averaged by site. Some of the soil conditions could not be included in the analysis because they were highly correlated between each other in the mortality models of both species (Appendix 1.5).

Mortality rates of forest re-vegetation projects in Wellington city appears to be low compared to similar studies (e.g. P A Handford \& Associates Ltd 2009; Sullivan et al. 2009; Smaill et al. 2011). However, there are two factors that should be taken into account to appropriately interpret the mortality rates recorded in this study. First, the biodiversity department of WCC compiled a list of suitable species for the early stages of forest re-vegetation projects within Wellington city. Wineberry, cabbage tree and lemonwood are among the most used species in these projects because of their high performance. Therefore, comparing the mortality rates of this study with the mortality rates of previous studies in Wellington city that was pooled across several species (e.g. P A Handford \& Associates Ltd 2009) may be an inappropriate analysis. Secondly, it is important to bear in mind the duration of this monitoring study when interpreting the mortality rates. The monitoring period of this research, six months after planting, is shorter than the suggested two year monitoring period to identify the success of a re-vegetation planting (Graham \& Filmer 2007; Ledgard \& Henley 2009). The short monitoring period does not include the effects of environmental variables in the mortality of seedlings across the entire year. Mortality probability of plants has been proved to increase in summer due to the drought conditions (Watson 1996). Furthermore, this research is likely to not include either the mortality manifested as a gradual decline in vigour 
(Franklin et al. 1987). Thus, mortality rates in this research may be underestimated.

Despite the limited mortality recorded in this study, results point towards management opportunities to maximise seedling survival within the first six months after planting. WCC and CG should implement the appropriate techniques and tools to mitigate the negative effects of water deficiency and grass competition. The use of mulch reduces the negative effects of both environmental variables (Porteous 1993; Ledgard \& Henley 2009). Models predicting the mortality of wineberry and cabbage trees also identified mulching as a crucial variable affecting seedling mortality. Transplanting in late autumn may assist the seedlings with overcoming the summer drought period (Porteous 1993). The disadvantage of transplanting in this time of the year is the seedling exposure to low winter temperatures (Porteous 1993). However, Wellington typically experiences mild temperatures throughout the winter (NIWA 2013). Mild temperatures are unlikely to damage the native plants (Sakai \& Wardle 1978). In accordance with the results of my study, grass control efforts should be focussed on keeping the grass shorter than the height of the seedlings. However, it is important to remember that grass control should be undertaken by implementing the appropriate techniques to avoid damaging the seedlings.

The low mortality (1.2\%) of lemonwood seedlings highlights the resilience of this species. Transplanting lemonwood seedling should be considered in the early stages of every forest re-vegetation project within Wellington City, especially in the challenging sites (e.g. sites that present poor soil conditions or weed problems).

Despite observable differences between re-vegetation sites led by CG and WCC, for example during the planting period, these differences do not appear to result in dissimilar mortality rates of the seedlings. WCC and CG both have comparable survival rates. Thus, WCC should continue supporting forest re-vegetation projects led by CGs, given the high survival rates of their 
re-vegetation sites. Furthermore, WCC should also continue supporting CGs given the numerous social benefits that projects led by CGs generate (Chapter 1).

A longer monitoring period (e.g. one year) will provide additional information about the effects of different seasons in the mortality of seedlings. By recording the mortality manifested as a gradual decline in vigour, a longer monitoring period will also refine our understanding about the relative importance of all the variables included in the overall models of this study (e.g. canopy cover overhead the seedling or soil conditions). In conclusion, additional information about the influence of these variables in the mortality of wineberry, cabbage tree and lemonwood seedlings over time, as well as in other species, will assist forest restoration projects to achieve more cost- and labour-efficient re-vegetation management. 



\section{A COHORT ANALYSIS OF TREE SEEDLING SURVIVAL FROM I TO 4 YEARS AFTER TRANSPLANTING.}

\section{ABSTRACT}

The best management techniques to maximise plant survival of forest re-vegetation projects in urban areas of New Zealand, along with the optimal time to undertake them, still need to be determined. In this study, I identify the most vulnerable time and the environmental variables involved in the mortality of wineberry (Aristotelia serrata), cabbage tree (Cordyline australis) and lemonwood (Pittosporum eugenioides) aged one to four years old. Lemonwood trees, independent of their age, experienced low mortality rates $(<2 \%)$. Mortality of wineberry and cabbage trees, in the initial three years after planting, was associated with environmental variables (soil conditions, slope, aspect and grass height) and size of the plants. The distribution of plants, based on microsite preferences determined by shade tolerance or water requirements, is crucial to maximise survival rates. Furthermore, site maintenance tasks (e.g. grass control) are still required after the seedling establishment period (2 years). Maintenance tasks should continue until the planted seedlings reach a size that allows the plants to overcome the negative effects of environmental conditions. A longer monitoring period covering an entire year will help refine our understanding of the effects of environmental variables on observed mortalities of wineberry and cabbage tree. Similar research of other commonly transplanted species within Wellington will help identifying the minimum height of plants so that maintenance tasks are not further required. Ultimately, identifying the minimum plant height will allow Wellington City Council and 
Community Groups to implement more cost and labour efficient re-vegetation management practices.

\section{INTRODUCTION}

There are numerous benefits associated with maintaining forested habitats in urban areas (Chapter 1 ). These benefits are increasingly threatened because native forests in urban areas have been declining due to anthropogenic activities (e.g. fire, urban development and the introduction of exotic species) (McDonnell 2007). In the last few decades, in an effort to retain and restore native forests and associated biodiversity in urban areas, government agencies and local community groups have established numerous re-vegetation projects (Given \& Meurk 2000; Clarkson et al. 2007). In New Zealand, transplanting native seedlings is a widely used restoration technique among these urban re-vegetation projects.

Transplanting native seedlings is more labour intensive and requires more funding than other re-vegetation techniques (Chapter 2). Therefore, maximising the survival rates of the seedlings after they have been transplanted is a key step in any re-vegetation project. In order to maximise seedling survival rates, it is necessary to understand the processes involved in plant mortality (Porteous 1993; Smaill et al. 2011). By understanding these processes, agencies executing revegetation projects can make informed decisions regarding timing and necessary management in their transplanting approach.

Numerous variables affect the mortality of New Zealand native seedlings. For example, non-native mammals proved to negatively affect the establishment of kapuka (Griselinia littoralis) and wineberry seedlings in the Waitutu Forest, Fiordland National Park (Wilson et al. 2006). High soil compaction and poor drainage also negatively affect survival of nine native species in Waitakere City, Auckland (Sullivan et al. 2009). Finally, weed control has been highlighted as 
very important for the survival of seven pioneer species in Sherry riverbank at Matariki (Smaill et al. 2011).

There are many manuals that describe techniques of transplanting seedlings that minimise the negative effects of environmental variables (e.g. Porteous 1993; Atkinson 1994; Davis \& Meurk 2001). However, results from previous research indicated that the relative importance of these environmental variables affecting seedling mortality can change over time following the transplanting (Tyler et al. 2008). Changes in the relative importance of limiting variables, according to age of the seedlings, have been predominantly overlooked in New Zealand. Thus, the best management techniques to maximise plant survival in urban areas of New Zealand, along with the optimal time to undertake them, still need to be developed (Sullivan et al. 2009).

Mortality rates for plants tend to decrease with time after seedlings are transplanted. Re-vegetation success can be accurately quantified after an establishment period of two years following the original transplanting (Graham \& Filmer 2007; Ledgard \& Henley 2009). Following the two initial years after planting, the probability of plant mortality in subsequent years becomes negligible (Graham \& Filmer 2007; Ledgard \& Henley 2009). P A Handford \& Associates Ltd (2009), based on the idea that reduced plant mortality is also associated with increases in canopy cover, suggested that no further maintenance or ongoing checks are required to ensure plant survival once $80-100 \%$ native canopy cover is achieved at a site. Furthermore, supplementary planting with secondary species can be undertaken once $80-100 \%$ native canopy cover is reached (P A Handford \& Associates Ltd 2009). The time required for seedlings to achieve an $80-100 \%$ canopy cover of the site varies depending on the species and the environmental variables (Marden et al. 2005). Forest re-vegetation sites in Wellington generally achieve these levels of canopy cover approximately 8 years after planting (P A Handford \& Associates Ltd 2009).

The two goals of this study are to identify the environmental variables influencing the cohort-specific mortality of one to four year old seedlings and 
the most vulnerable time period of these seedlings. To achieve these goals, I investigated the mortality rates of seedlings, transplanted between 2008 and 2011, in forest re-vegetation projects within Wellington City, New Zealand.

\section{METHODS}

\subsection{Species and study sites}

Wineberry (Aristotelia serrata), cabbage tree (Cordyline australis) and lemonwood (Pittosporum eugenioides) were the three species selected for this research. These species, due to their fast growing rates, are pioneer species commonly transplanted within the Wellington City forest re-vegetation projects (Chapter 2). The fastest period of growth for these species occurs after the seedlings establishment period, approximately two years after transplanting (Marden et al. 2005).

Eleven forest re-vegetation projects within Wellington City (Figure 8) were selected for this study. Sites were selected because wineberry, cabbage tree and lemonwood were commonly transplanted in these sites between 2008 and 2011.

The forest re-vegetation projects followed similar site preparation, transplanting and site maintenance processes. Grass was mowed two weeks prior to planting. Berhampore nursery, located in Wellington City, grew the seedlings in $\mathrm{PB}_{3}$ containers for all sites. Seedlings were transplanted by either staff of the Wellington City Council (WCC) or members of a local community group (CG). Individual seedlings were transplanted approximately one metre apart. Planting was executed between June and August to minimise stress caused by drought conditions (Porteous 1993). Each site took preventative measures to control grass growth (e.g. mowing or herbicides). 


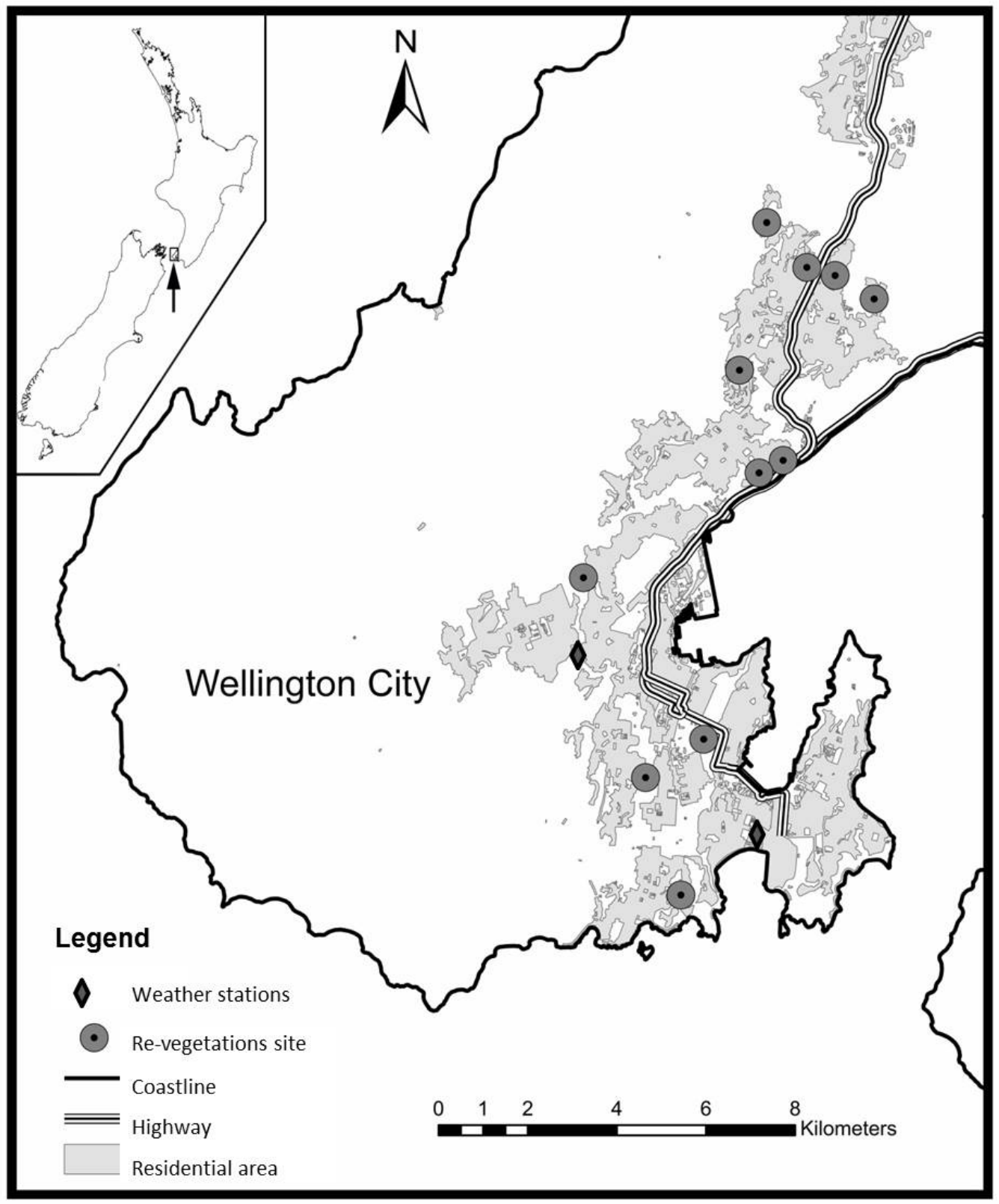

Figure 8: Location of the 11 re-vegetation sites planted between 2008 and 2011. 


\subsection{Data sampling}

I monitored the status of 1406 plants over a six month period. The plants were between 1 and 4 years post-transplanting at the start of the monitoring (Appendix 2.1). The start of the monitoring period varied among sites, but all the monitoring occurred between May 2012 and March 2013 (Appendix 2.2). Mortality of plants $\geqslant 2$ years old was a rare event. Therefore, it was necessary to monitor a large sample size. I aimed to monitor 90 seedlings from each year-group per site. However, the sites contained different quantities of seedlings per species and per year (Appendix 2.1) due to inaccurate records of the re-vegetation site or because seedlings died prior to the monitoring period of this research.

On the initial measuring date (henceforth, day o), seedlings were individually tagged and their location was recorded on a detailed site map to assist with locating. Six months after day o, seedlings were inspected again to determine whether they were alive or dead. The cause of death ("standing", "uprooting" or "mowed") was recorded for the plants that had died. I considered seedlings I was unable to relocate during the six-month site visit as dead. Additionally, I recorded the height of the plants, on day o and 6 months after, to assess plant growth. Height of the plant was recorded by measuring the length between the ground and the highest green leaf of the plant. Negative growth values were recorded because some plants experienced loss of leaves or damage in their branches.

I recorded certain environmental variables to identify their influence in the cohort specific mortality of one to four year old seedlings. I used the same procedure described in Chapter 2 to measure these variables (Table 5). 
Table 5: Factors affecting mortality of plants and the correspondent variables recorded in this study

Factor

\begin{tabular}{ll}
\hline & Plant height \\
Conditions of the plant on day o & Trunk diameter (cabbage tree) \\
& Crown area (wineberry and lemonwood) \\
& Presence of damaged branches \\
\hline Water availability & Rainfall received over the 6 month period \\
\hline Microsite conditions & Mulch \\
\hline Slope & Aspect \\
Canopy cover overhead the seedling \\
\hline Herbivore levels
\end{tabular}




\subsection{Data analysis}

Crown measurements, the aspect of each seedling and the presence/absence of rodents were modified prior to data analysis. Crown length and crown width at day o were combined to calculate the crown area, assuming an elliptical shape of the crown, using the following formula: $\mathrm{CA}\left(\mathrm{cm}^{2}\right)=\pi \frac{(\mathrm{Cm} / 2)(\mathrm{Cp} / 2)}{100}$ (Sah et al. 2004), where $\mathrm{Cm}$ is the crown maximum width of the seedling $(\mathrm{mm})$ and $\mathrm{Cp}$ is the crown perpendicular width (mm). Based on the amount of tracking tunnels occupied, I calculated the relative abundance of rodents for each site. The aspect of the slope where the plant was planted, or northerness, was calculated by subtracting 180 from actual compass readings for each seedling. This index has a maximum value of 180 when aspect is due north and a value of zero when the aspect is due south. Seedlings that were in flat areas, because they were neither facing south nor north, were assigned a northerness value of 90.

Prior to data analysis, seedlings that died as a result of mowing were excluded because their cause of mortality was unrelated to other variables measured at the site. To study whether the influence of environmental factors on the mortality of plants differs before and after establishment, seedlings were divided into two groups: 1) Pre-establishment. Group constituted of one year old seedlings (transplanted one year prior to this research). 2) Post-establishment. Group constituted of two years or older seedlings (transplanted at least 2 years before this research).

Mixed effects models were generated for each group of plants, pre- and post-establishment, that experienced a mortality rate of at least $4 \%$. Estimating the contribution of environmental variables on plant mortality, based on mixed effects model techniques, proved to be difficult given the limited information of the dependent variable (mortality) in groups that experienced mortality rates lower than $4 \%$.

To account for additional variation among sites, each site was treated as a random effect. In order to avoid multicollinearity, variables that presented high 
correlations $(r>0.8)$ with other variables were extracted from the model prior to analysis. This process was repeated until the highest correlation coefficient between variables was lower than 0.8 in each mortality model.

After highly correlated variables were removed, a stepwise backward regression procedure (Spiegelhalter et al. 2002) was used to remove variables that did not explain variation in the mortality of plants. The stepwise backward regression was based on a minimization of AIC values (Shtatland et al. 2001). As suggested by Shtatland et al. (2001), this method improves the predictive abilities and interpretation of results. If the removal of a variable resulted in a decrease in the AIC value of the model, the factor was removed from the model (Bates 2010). After removing redundant variables, a minimum adequate mortality model (henceforth, overall model) was generated only including variables that have an important influence on plant mortality.

Following Bates (2010), in order to identify the most important variables in each overall model, I compared the AIC increase ( $\triangle \mathrm{AIC}$ ) following removal of each variable from the overall model. Variables, whose removal resulted in an increase of AIC by more than 10 units, were considered to be the more important variables within the overall model (Burnham \& Anderson 2002).

Statistical analyses were executed using the R-Program ( $R$ Development Core Team 2012) and the LME4 package (Bates et al. 2012). Cubic smoothing splines (Reinsch 1967) were generated to assist the interpretation of the relationship between explanatory factors and plant mortality. 


\subsection{Mortality rates}

Mortality rates of the seedlings varied depending on their age (Table 6). These variations were species-specific. The mortality rates of wineberry seedlings decreased with increasing age. Cabbage tree mortality rates also decreased over time. However, cabbage tree individuals, transplanted in 2008, experienced high mortality rates. Lemonwood individuals experienced the lowest mortality rates across all age classes. Mortality rates of lemonwood also decreased over time after the initial transplanting.

Most of the mortality events were classified as "standing" (Table 7). However, 15 plants were also considered dead because they could not be found during site investigations.

The crown area, recorded on day $\mathrm{o}$, was the most important variable (19.12 $\triangle \mathrm{AIC}$ ) explaining the mortality of wineberry transplanted in 2011. A negative linear relationship occurred between mortality probability and crown area (Figure 9). Soil compaction, the second most influential variable, is positively correlated with the mortality probability (Table 8 ). The slope of the transplanting site and the height of the grass also increase the probability of mortality. Aspect and phosphorus availability in the soil are the least important variables $(<4.6 \triangle \mathrm{AIC})$ included in the overall model. These variables are negatively correlated with mortality of wineberry transplanted in 2011 (Table 8).

The height of the plant, recorded on day o, was the most influential variable in the mortality probability of wineberry transplanted in 2009 and 2010. The relationship between mortality probability and height was linear (Figure 9). Removing this variable from the model generated a $\triangle \mathrm{AIC}$ of 30.82 . The difference was at least 1o AIC units higher than the difference of excluding any 
of the other variables from the model. Probability of mortality was positively correlated with grass height and $\mathrm{N}$ content in soil (Table 8).

The height, recorded on day o, of the cabbage tree seedlings transplanted in 2011 was the most important variable explaining their probability of mortality (17.06 $\triangle$ AIC). Shorter plants had higher mortality probabilities than taller plants. Individuals taller than one meter had a very low mortality probability (Figure 9). $\mathrm{N}$ content in the soil and the slope, included in the overall model, were positively correlated with the mortality probability.

Due to the low $(<4 \%)$ mortality rates observed for lemonwood, no statistical analysis was used to identify the contributions of variables involved in lemonwood mortality. Similarly, no model was generated for cabbage trees transplanted between 2009-10. Cabbage trees transplanted in 2008 experienced a high mortality $(17.5 \%)$. Seven dead trees were located in one site, Churton Park, where I monitored ten individuals (Appendix 2.1). Data were not analysed because a disease, referred to as "sudden decline", was the assumed cause of mortality of these seedlings. Additionally, numerous researchers have already investigated the susceptibility of cabbage tree to be affected from this diseases (e.g. Beever et al. 1996; Harris 2002).

Seedlings that were transplanted by community groups experienced slightly higher mortality rates $(5.4 \%)$ than seedlings transplanted in sites led by WCC $(3.9 \%)$.

\subsection{Growth}

Two-year-old and older seedlings experienced higher growth than one year old seedlings. However, the growth of seedlings varied across species. Older wineberry individuals grew more than younger individuals (Figure 10). Variation in growth between wineberry of similar age increased over time. Older cabbage trees also experienced higher growth rates than younger individuals. However, variation in growth between cabbage trees of the similar 
age decreased over time. The growth of different aged lemonwood trees did not follow a clear pattern. However, variation in growth among individuals of this species also increased as age increased.

Plant growth was positively correlated with the height of the individuals recorded on day o (Figure 11). Growth of all species increased as height recorded on day o increased (Figure 11). Wineberry plants taller than 2.5 metres reached a growth peak of approximately o.6 metres over 6 months (Figure 11). Cabbage trees and lemonwood trees reached their growth peak at approximately 0.2 metres, at a lower height than wineberries (1-1.5 metres).

Table 6: Mortality rates, per six months, and sample size of wineberry, cabbage tree and lemonwood planted between 2008 and 2011

\begin{tabular}{ccccccc} 
Year planted & Wineberry & \multicolumn{2}{c}{ Cabbage tree } & \multicolumn{2}{c}{ Lemonwood } \\
& Dead seedlings & $\mathrm{N}^{a}$ & Dead seedlings & $\mathrm{N}^{a}$ & Dead seedlings & $\mathrm{N}^{a}$ \\
\hline 2008 & $\mathrm{NA}$ & $\mathrm{NA}$ & $17.5 \%$ & 40 & $\mathrm{NA}$ & $\mathrm{NA}$ \\
$2009-10$ & $4.1 \%$ & 221 & $3.0 \%$ & 198 & $1.4 \%$ & 213 \\
2011 & $7.7 \%$ & 272 & $5.5 \%$ & 199 & $2.0 \%$ & 254
\end{tabular}

a Sample size

Table 7: Mortality causes of wineberry, cabbage tree and lemonwood seedlings planted between 2008 and 2011

Cause of mortality Wineberry Cabbage tree Lemonwood

\begin{tabular}{lccc}
\hline Standing & 21 & 8 & 5 \\
Uprooting & 0 & 5 & 0 \\
Mowed $^{a}$ & 1 & 0 & 0 \\
Missing & 8 & 4 & 3 \\
Sudden decline & NA & 7 & NA
\end{tabular}

$a$ excluded from the model 
Table 8: Overall models predicting probability of mortality of wineberry seedlings and cabbage tree seedlings, transplanted between 2009 and 2011 , and AIC increase after removing each variable from the model

\begin{tabular}{|c|c|c|c|c|c|c|c|c|c|c|}
\hline Species & Year planted & AIC & LogLik & Deviance & Variable & Estimate & Std. Error & $Z$ value & $\operatorname{Pr}(>|z|)$ & $\begin{array}{l}\text { Increase in model AIC } \\
\text { if the variable is removed }\end{array}$ \\
\hline \multirow{7}{*}{ Wineberry } & \multirow{7}{*}{2011} & \multirow{7}{*}{113.70} & \multirow{7}{*}{-47.87} & \multirow{7}{*}{$95 \cdot 73$} & (Intercept) & 7.91 & $5 \cdot 42$ & 1.46 & 0.14 & \\
\hline & & & & & Crown area $\left(\mathrm{cm}^{2}\right)$ & -0.00 & 0.00 & $-3 \cdot 44$ & 0.00 & 19.12 \\
\hline & & & & & Slope $\left(^{\circ}\right)$ & 0.07 & 0.02 & 3.08 & 0.00 & $7 \cdot 51$ \\
\hline & & & & & Northerness $\left({ }^{\circ}\right)$ & -0.02 & 0.01 & -1.83 & 0.07 & 1.37 \\
\hline & & & & & Grass height & 1.67 & 0.60 & 2.77 & 0.01 & $5 \cdot 71$ \\
\hline & & & & & Soil compaction $\left(\mathrm{kg} / \mathrm{cm}^{2}\right)$ & 0.43 & 0.13 & $3 \cdot 35$ & 0.00 & 9.07 \\
\hline & & & & & P content $(\mathrm{mg} / \mathrm{kg})$ & -0.32 & 0.14 & -2.35 & 0.02 & 4.26 \\
\hline \multirow{4}{*}{ Wineberry } & \multirow{4}{*}{$2009 / 10$} & \multirow{4}{*}{46.10} & \multirow{4}{*}{-16.05} & \multirow{4}{*}{32.10} & (Intercept) & -12.54 & 5.22 & -2.40 & 0.02 & \\
\hline & & & & & Height $(\mathrm{mm})$ & -0.01 & 0.00 & -2.92 & 0.00 & 30.82 \\
\hline & & & & & Grass height & 0.07 & 0.04 & -1.36 & 0.12 & 16.27 \\
\hline & & & & & $\mathrm{N}$ content $(\%)$ & 53.41 & 18.05 & 2.96 & 0.00 & 20.64 \\
\hline \multirow{4}{*}{ Cabbage tree } & \multirow{4}{*}{2011} & \multirow{4}{*}{64.92} & \multirow{4}{*}{-27.46} & \multirow{4}{*}{54.92} & (Intercept) & -8.90 & 2.89 & -3.08 & 0.00 & \\
\hline & & & & & Height (mm) & -0.01 & 0.00 & -3.40 & 0.00 & 17.06 \\
\hline & & & & & Northerness $\left({ }^{\circ}\right)$ & 0.14 & 0.06 & 2.54 & 0.01 & 6.04 \\
\hline & & & & & $\mathrm{N}$ content $(\%)$ & 61.23 & 17.00 & 3.60 & 0.00 & 11.02 \\
\hline
\end{tabular}



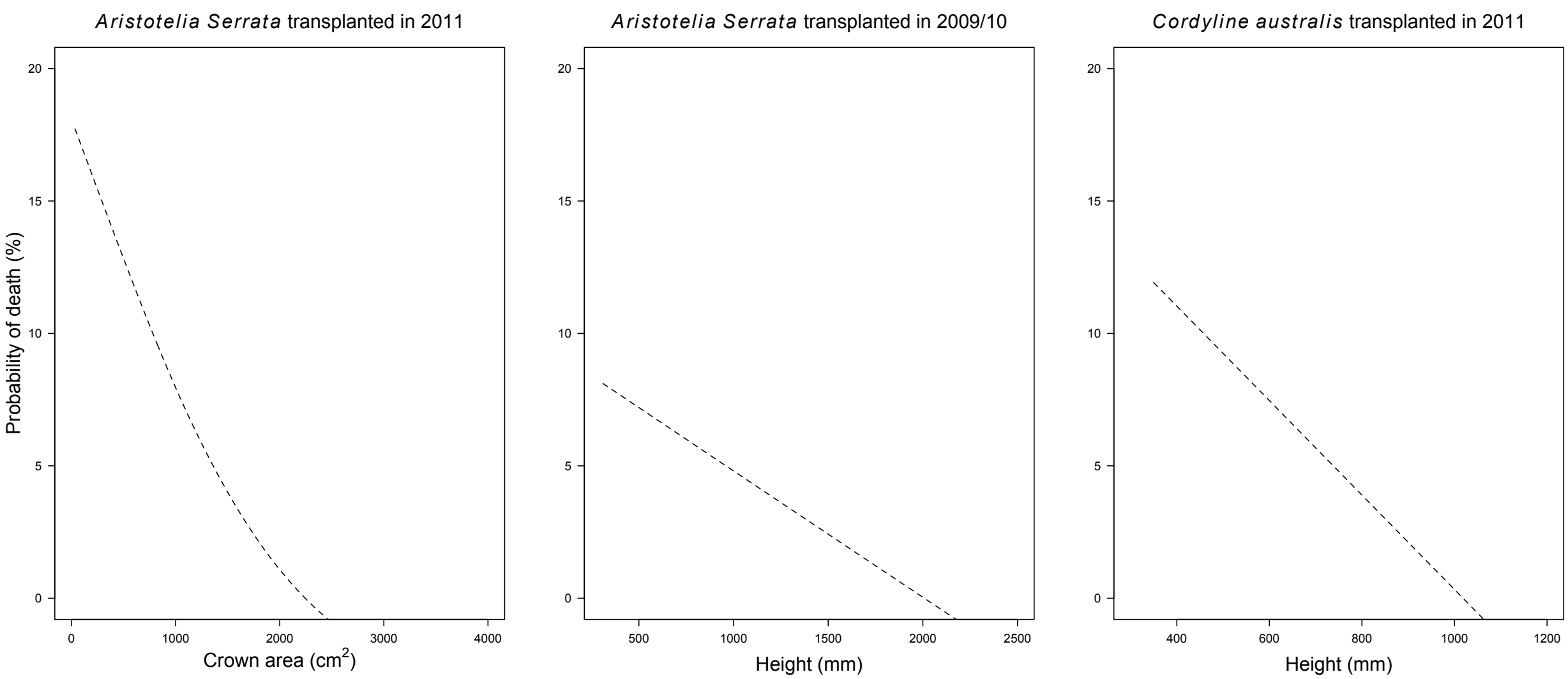

Figure 9: Cubic smoothing splines of the probability of mortality, over a 6 month period, versus crown area and height on day o of wineberry and cabbage trees transplanted between 2009 and 2011. 

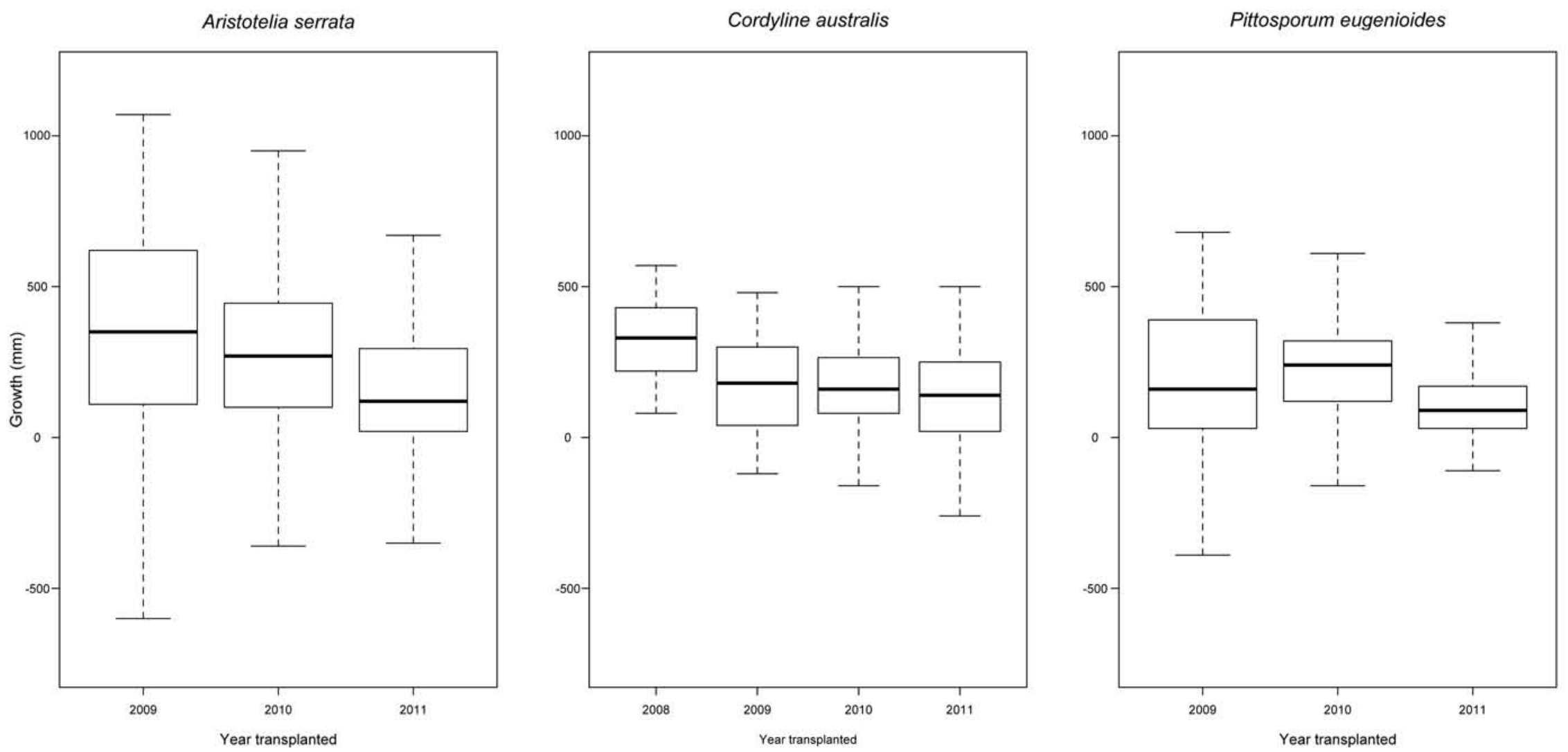

Figure 10: Change in height (growth) over a 6 month period of wineberry, cabbage tree and lemonwood seedlings transplanted between 2008 and 2011. 


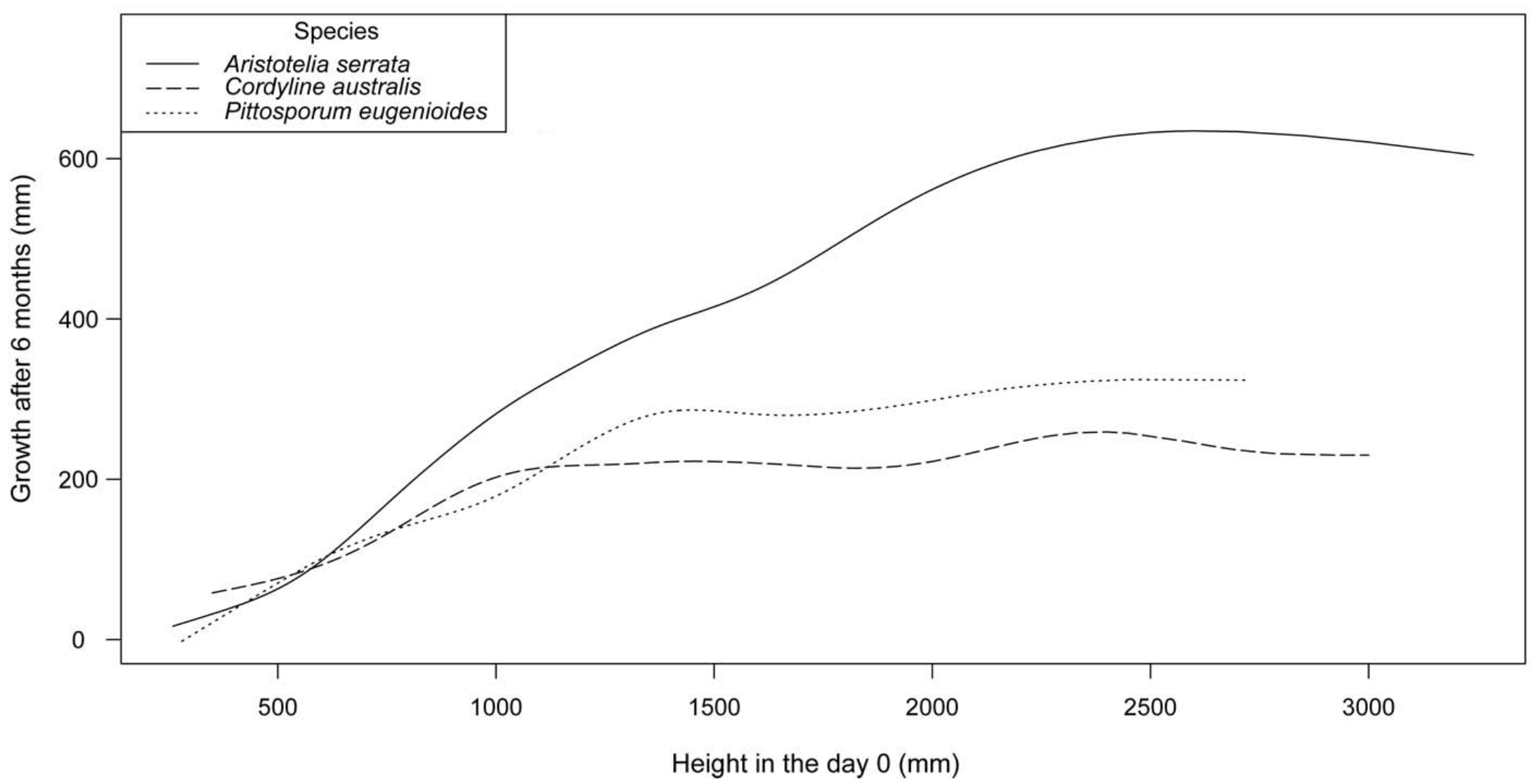

Figure 11: Cubic smoothing splines of the height, measured on day o, and height growth 6 months after of wineberry, cabbage tree and lemonwood transplanted between 2008 and 2011. 
Over the first three years of a re-vegetation project of native trees in Wellington, the most consistently important variable associated with mortality of wineberry and cabbage tree was the size of the plant. Larger individuals, of both species, experienced lower survival rates compared to smaller plants. However, other variables (e.g. soil conditions and aspect) also influence mortality. The influence of these variables on plant mortality varied over time and among species.

Crown area and height, recorded on day o, were crucial variables in the mortality of wineberry independent of their age. Height was also important in the mortality of 1-year old cabbage trees. Seedlings suffering high levels of stress create less biomass than those seedlings experiencing lower level of stress (Watson 1996). Consequently, plants that struggle to create biomass are less likely to establish due to the negative effects of sporadic environmental variables, such as extensive droughts (Silvertown \& Charlesworth 2009).

The probability of mortality of the plants monitored during this research decreased after the seedling establishment period (2 years). Thus, site maintenance during these first two years is crucial to maximise survival rates (Handford 2002; Ledgard \& Henley 2009). However, some residual mortality following the establishment period may remain (Smaill et al. 2011). WCC reports suggest that in order to ensure plant survival, maintenance tasks may be required until high levels of native canopy cover are achieved (up to 8 years after planting) (P A Handford \& Associates Ltd 2009). However, Cook (1980) and Mencuccini et al. (2005) suggested that size of the plants is a more accurate predictor of plant mortality than age (time after transplanting). The minimum size (e.g. height or crown area) required for plants to successfully overcome the negative effects of environmental variables vary among species (Sullivan et al. 2009). Based on the results of my research (Figure 9), cabbage trees taller than one meter possess the ability to overcome adverse environmental conditions. However, the minimum size for wineberry to overcome negative environmental 
effects is approximately two metres (Figure 9). These differences in minimum height may be due to differences in species traits. Therefore, similar studies of other native species will assist in providing the necessary information to identify an average height value where no further maintenance is required. The minimum size where negative environmental effects can be overcome in this research was based on a mortality rate of $\mathrm{o} \%$. However, re-vegetation approaches that achieve higher mortality rates may be more cost-effective depending on site characteristics, managing agencies and species planted.

Plant mortality is often a consequence of many variables. By analysing the relative importance of numerous variables, different equations to predict plant mortality have been generated (Porté \& Bartelink 2002; Hickler et al. 2012). However, these equations can not be widely applied because plant mortality appears to be site- and species-specific (Holzwarth et al. 2013). In my research, the height of the plant and the crown area proved to be a crucial factor of plant mortality, but the mortality was likely to be a consequence of the relationships between plant size and several environmental variables. For example, results from the statistical analysis highlight the relationship between grass height and plant height as an important variable in the mortality of wineberry following the first 3 years after transplanting has been completed (Table 8). Grass is a greater threat, in terms of competition, to short plants than to tall plants. The results of my study also highlight the importance of other environmental variables such as soil conditions, slope and aspect in the mortality of wineberry and cabbage tree.

The models point out that soil compaction and the $\mathrm{N}$ content in soil are among the most important variables for wineberry and cabbage tree seedlings (Table 8). These findings support the results from similar research in other New Zealand urban areas (e.g. Sullivan et al. 2009). However, the high correlation among the parameters recorded to assess soil conditions (Appendix 2.3) impeded an accurate determination of the relative importance of each parameter in plant mortality. 
One-year-old wineberry and cabbage trees planted on steep slopes experienced higher mortality probabilities than those transplanted in generally flat areas. The differences in mortality probabilities according to the slope, may be caused by soil erosion. Soil and rock movements often occur after planting, as a result loosened soil. The movements are more likely to damage plants located on steep slopes than plants located in flat areas (Bochet \& García-Fayos 2004).

Northerness was included in the overall model of 2-year old wineberry. The preference of this species for moist places (Pratt 1999) may contribute to the higher survival rate of individuals facing south compared to individuals facing north. However, northerness was less important than other variables in explaining mortality probabilities of wineberry plants (1.37 $\triangle \mathrm{AIC})$.

Four-year-old cabbage trees experienced a high mortality rate. Based on the descriptions provided by Beever et al. (1996) and Simpson (2001), I hypothesise that a disease, sudden decline, was the cause of all the dead cabbage trees. Furthermore, it is probable that the disease spread to neighbouring plants, given that the dead individuals occurred in only one site. Currently, there is no treatment for this disease (Simpson 2001; Liefting et al. 2007).

Less than $2 \%$ of the lemonwood plants died in the 6 months after their initial measurement date, independent of age. Due to its high resilience, it might be warranted to consider transplanting this species in the early stages of most forest re-vegetation project within Wellington (in sites where other species suffer high mortality rates such as highly disturbed sites and sites where weeds are a problem).

Many studies suggest that plant growth increases over time after planting (e.g. Busell 1968; Marden et al. 2005). However, results from the growth of individuals pooled across years showed that, despite their time after planting, taller and bigger plants had higher growth rates than shorter and smaller plants (Figure 10 and 11). Thus, the height of the plant appears to be a better suited predictor for plant growth than time after planting. Height can also be used as a tool to 
determine the need for future maintenance management, as well as the optimal timing to begin transplanting secondary species.

The results of my study are based on data sampled between late winter and early summer. I did not record all possible effects of the environmental conditions on plant mortality across the entire year. For example, I did not evaluate the influence of summer droughts, known to increase mortality probability of plants (Mack \& Pyke 1984; Watson 1996). Additionally, the effects of environmental variables also change over time after transplanting (Tyler et al. 2008). A longer monitoring period would refine the mortality models to determine how these effects change over time since transplanting.

The results of this research suggest that, when compared to similar studies (e.g. Sullivan et al. 2009; Smaill et al. 2011; Johnson 2012), WCC and CG are achieving high survival rates under their current re-vegetation approach. However, my results are based on a six month monitoring period and other studies are based on longer monitoring periods.

Based on the mortality results of my study, there are some recommendations for improving cost and labour efficiency of WCC and CG projects. The effects of environmental variables in the mortality of the plants vary depending on species. Therefore, an appropriate distribution of the seedlings in the transplanting site, based on the species-preferences, is crucial for maximising survival rates. For example, results highlighted that wineberry performs better in north facing slopes while cabbage tree prefers south facing slopes. WCC and CG should continue undertaking maintenance tasks for longer than two years after transplanting, especially weeding around smaller plants. The use of highly visible markers near each seedling might assist locating these small plants and avoid losses to mowing. In order to identify when further maintenance is no longer required to ensure plant survival, WCC and CG should focus on the average height of the individuals achieved at a site rather than time after transplanting. Therefore, WCC and CGs management plans should include a post-planting monitoring method for recording the growth of some seedlings. 
Monitoring the growth of these seedlings will provide information for WCC and CGs to adopt appropriate maintenance tasks. WCC should also continue promoting community-based projects, because the seedlings transplanted by these groups appears to experience similar survival rates to seedlings transplanted by WCC. 



\section{GENERAL CONCLUSIONS}

The mortality rates of seedlings varied among the three species recorded in this study. Wineberry seedlings experienced the highest mortality of the three species. However, mortality rates of this species, as well as those of cabbage trees decreased with the age of the plant. Lemonwood seedlings experienced the lowest mortality rates of the three species.

Following the initial 6 months after transplanting, water availability and the competition with grass were the most crucial variables in the mortality of wineberry and cabbage trees. The mortality of plants aged one to three years, the crucial factors were combinations between the size of the plant (height or crown area) and certain environmental covariates (soil conditions, slope, aspect and grass height). Four year old cabbage trees experienced high mortality rates, potentially due to a disease infection, known as sudden decline. Due to the low mortality rates of lemonwood, the variables influencing mortality were not analysed.

In order to maximise survival rates of seedlings used in the forest re-vegetation projects in Wellington, it is important that WCC and CG match seedlings to site-specific conditions. The distribution should be based on the microsite preferences of each species, such as shade tolerance or water requirements. Furthermore, maximising survival rates of wineberry and cabbage tree seedlings requires transplanting techniques and maintenance tasks that mitigate the effects of grass competition and water availability (e.g. mowing the grass or planting earlier in the year). Maintenance tasks may continue until plants have achieved a certain height (typically one to two metres height) that allows them to overcome the negative effects of environmental 
variables. A longer monitoring period will inform WCC and CGs about the effects of the variables involved in the mortality of plants and the changes in these variables over time. Similar research of commonly transplanted species within forest re-vegetation projects in Wellington city may assist in determining the variables involved in the mortality of most of the most utilised seedlings. Additional research will also assist planters to identify the crucial stages of the re-vegetation (e.g. the minimum height required of plants to overcome grass competition) so they can achieve more cost- and labour-efficient re-vegetation management. 


\section{BIBLIOGR A PHY}

Allen W, Kilvington M 2009. Seedling quality, handling and establishment. URL http://www.tussocks.net.nz/forestry/management/ seedlingqualityhandlingestablishment.html.

Alvey AA 2006. Promoting and preserving biodiversity in the urban forest. Urban Forestry \& Urban Greening 5:195-201.

Anastasiou CJ, Brooks JR 2003. Effects of soil $\mathrm{pH}$, redox potential, and elevation on survival of Spartina patens planted at a west central Florida salt marsh restoration site. Wetlands 23:845-859.

Arnold MA, McDonald GV, Bryan DL 2005. Planting depth and mulch thickness affect establishment of green ash (Fraxinus pennsylvanica) and bougainvillea goldenraintree (Koelreuteria bipinnata). Journal of Arboriculture 31:163-170.

Atkinson I 1994. Guidelines to the development and monitoring of ecological restoration programmes. New Zealand. Dept. of Conservation DOC.

Atkinson IA, Cameron EK 1993. Human influence on the terrestrial biota and biotic communities of New Zealand. Trends in Ecology \& Evolution 8:447 451.

Bates D, Maechler M, Bolker B 2012. lme4: Linear mixed-effects models using $\mathrm{S}_{4}$ classes. URL http://CRAN.R-project.org/package=lme4. R package version 0.999999-0.

Bates DM 2010. lme4: Mixed-effects modeling with r. URL http://lme4. r-forge. r-project. org/book .

Bee J, Kunstler G, Coomes D 2007. Resistance and resilience of New Zealand tree species to browsing. Journal of Ecology 95:1014-1026. 
Beever R, Forster R, Rees-George J, Robertson G, Wood G, Winks C 1996. Sudden decline of cabbage tree (Cordyline australis): search for the cause. New Zealand Journal of Ecology 20:53-68.

Blakemore L, Searle P, Daly B 1987. Methods for chemical analysis of soils. Department of Scientific and Industrial Research.

Bochet E, García-Fayos P 2004. Factors controlling vegetation establishment and water erosion on motorway slopes in Valencia, Spain. Restoration Ecology 12:166-174.

Boffa Miskell Ltd 1998. Wellington's native vegetation: a brief survey of early historical records. Technical report.

Boffa Miskell Ltd 2003. Wellington ecodomain delineation. Technical report.

Buchan D 2007. Not just trees in the ground: the social and economic benefits of community-led conservation projects. WWF-New Zealand.

Buchman R, Pederson S, Walters N 1983. A tree survival model with application to species of the Great Lakes region. Canadian Journal of Forestry 13:601-608.

Burke MJ, Grime J 1996. An experimental study of plant community invasibility. Ecology 77:776-790.

Burnham K, Anderson D 2002. Model selection and multi-model inference: a practical information-theoretic approach. Springer.

Busell WT 1968. The growth of some New Zealand trees. I. Growth in natural conditions. New Zealand Journal of Botany 6:63-75.

Camara A 2011. The role of shrubs and rabbit herbivory in the ecological restoration of the drylands of south-central New Zealand. Ph.D. thesis, University of Otago.

Clarkson BD, Wehi PM, Brabyn L 2007. Bringing nature back into cities: urban land environments, indigenous cover and urban restoration. Technical Report 
Contract Report No.52, CBER, Hamilton, New Zealand: Centre for Biodiversity and Ecology Research, Department of Biological Sciences, School of Science and Engineering, The University of Waikato.

Cook RE 1980. Germination and size-dependent mortality in Viola blanda. Oecologia 47:115-117.

Davis M, Meurk C 2001. Protecting and restoring our natural heritage - a practical guide. Technical report, Department of Conservation, Christchurch.

Davis MR 2009. Establishing indigenous forest on erosion-prone grassland: land areas, establishment methods, costs and carbon benefits. New Zealand Forest Research Institute.

Douglas GB, Dodd MB, Power IL 2007. Potential of direct seeding for establishing native plants into pastoral land in New Zealand. New Zealand Journal Of Ecology 31:143-153.

Ferm A, Hytonen J, Lilja S, Jylha P 1994. Effects of weed-control on the early growth of Betula pendula seedlings established on an agricultural field. Scandinavian Journal of Forest Research 9:347-359.

Franklin JF, Shugart H, Harmon ME 1987. Tree death as an ecological process. BioScience 37:550-556.

Gabites I 1993. Wellington's living cloak: a guide to the natural plant communities. Wellington Botanical Society.

Given D, Meurk C 2000. Biodiversity of the urban environment: the importance of indigenous species and the role urban environments can play in their preservation.

Graham S, Filmer M 2007. Survey sheds light on seedling survival. Farming Ahead 187:56-59. 
Greater Wellington Regional Council 2010. Wellington Regional native plant guide- Revised edition 2010. Technical Report 0-909016-94-1, Greater Wellington Regional Council.

Greater Wellington Regional Council 2012. Air, land and water in the Wellington region - state and trends. Technical Report GW/EMI-G-12/152, Greater Wellington Regional Council.

Haan NL, Hunter MR, Hunter MD 2011. Investigating predictors of plant establishment during roadside restoration. Restoration Ecology 20:315-321.

Hamberg L, Lehvävirta S, Minna ML, Rita H, Kotze DJ 2009. The effects of habitat edges and trampling on understorey vegetation in urban forests in Helsinki, Finland. Applied Vegetation Science 11:83-98.

Hamilton D, Edwards B 1976. Modeling the probability of individual tree mortality. Technical Report INT-185, U.S.D.A. For. Serv. Res. Pap.

Handford P 2002. Native forest monitoring: a guide for forest owners and managers. FRONZ.

Harris W 2002. The cabbage tree. Journal of the Royal New Zealand Institute of Horticulture 5:3-9.

Harris W, Beever RE, Parkes S, Webster P, Scheele S 2003. Genotypic variation of height growth and trunk diameter of Cordyline australis (Lomandraceae) grown at three locations in New Zealand. New Zealand Journal Of Botany 41:637653.

Hickler T, Vohland K, Feehan J, Miller PA, Smith B, Costa L, Giesecke T, Fronzek S, Carter TR, Cramer W, et al. 2012. Projecting the future distribution of european potential natural vegetation zones with a generalized, tree speciesbased dynamic vegetation model. Global Ecology and Biogeography 21:50-63. 
Hill R, Sparling G, Frampton C, Cuff J 2003. National soil quality review and programme design. Technical report, Ministry for the Environment of New Zealand.

Holzwarth F, Kahl A, Bauhus J, Wirth C 2013. Many ways to die-partitioning tree mortality dynamics in a near-natural mixed deciduous forest. Journal of Ecology 101:220-230.

Husheer S, Robertson A, Coomes D, Frampton C 2006. Herbivory and plant competition reduce mountain beech seedling growth and establishment in New Zealand. Plant Ecology 183:245-256.

Johnson BA 2012. Ecological restoration of the Wairio wetland, Lake Wairarapa: water table relationships and cost-benefit analysis of restoration strategies. Master's thesis, Victoria University of Wellington.

Johnson P 1976. Effects of soil phosphate level and shade on plant growth and mycorrhizas. New Zealand Journal of Botany 14:333-340.

Karori Reservoir Wildlife Sanctuary Trust 2008. Annual repot July 2007 - June 2008. Technical report, Karori Reservoir Wildlife Sanctuary Trust, Wellington.

Konijnendijk CC 2008. The forest and the city: the cultural landscape of urban woodland. Springer.

Leco 2003. Total/organic carbon and nitrogen in soils. Technical report, LECO Corporation St. Joseph, MO.

Ledgard N, Henley D 2009. Native plant establishment along riparian margins of the Sherry River, Motueka catchment. Technical report, Scion.

Lhotka JM, Loewenstein EF 2008. Influence of canopy structure on the survival and growth of underplanted seedlings. New Forests 35:89-104.

Liefting LW, Beever RE, Andersen MT, Clover GR 2007. Phytoplasma diseases in New Zealand. Bulletin of Insectology 60:165. 
Mack RN, Pyke DA 1984. The demography of Bromus tectorum: the role of microclimate, grazing and disease. The Journal of Ecology 72:731-748.

Marden M, Rowan D, Phillips C 2005. Stabilising characteristics of New Zealand indigenous riparian colonising plants. Plant and Soil 278:95-105.

McDonnell MJ 2007. Restoring and managing biodiversity in an urbanizing world filled with tensions. Ecological Management \& Restoration 8:83-84.

McGlone M 1989. The Polynesian settlement of New Zealand in relation to environmental and biotic changes. New Zealand Journal of Ecology 12:115129.

McGlone MS 2006. Becoming New Zealanders: Immigration and the formation of the biota, volume 186. Springer-Verlag Berlin, Berlin.

Mencuccini M, Martínez-Vilalta J, Vanderklein D, Hamid H, Korakaki E, Lee S, Michiels B 2005. Size-mediated ageing reduces vigour in trees. Ecology Letters 8:1183-1190.

Meurk C, Swaffield S 2000. A landscape ecological framework for indigenous regeneration in rural New Zealand-Aotearoa. Landscape and Urban Planning 50:129-144.

Ministry for Culture and Heritage 2012. The Otari-Wilton's Bush Scenic Reserve. URL http://www.nzhistory.net.nz/media/photo/ wilton-bush-scenic- reserve.

Miskelly C, Empson R, Wright $\mathrm{K}$ 2005. Forest birds recolonising Wellington. Notornis 52:21-26.

Mitcalfe B 2002. Native planting for streamsides in Wellington Conservancy. Technical report, DOC Department of Conservation.

Muratet A, Machon N, Jiguet F, Moret J, Porcher E 2007. The role of urban structures in the distribution of wasteland flora in the Greater Paris Area, France. Ecosystems 10:661-671. 
National Pest Control Agencies 2012. Modified McLean Rabbit Infestation Scale. URL http://www.npca.org.nz/images/stories/NPCA/PDF/modified\% 20mclean\%20rabbit\%20infestation $\% 20$ scale $\% 202012$. pdf.

NIWA 2013. The National Climate Database. URL http://cliflo.niwa.co.nz/.

Ogden J, Gilbert J 2009. Prospects for the eradication of rats from a large inhabited island: community based ecosystem studies on Great Barrier Island, New Zealand. Biological Invasions 11:1705-1717.

Oliver-Smith N 2012. Personal communication.

Olsen S 1954. Estimation of available phosphorus in soils by extraction with sodium bicarbonate. Circular (United States. Dept. of Agriculture). U.S. Dept. of Agriculture.

Overdyck E, Clarkson BD 2012. Seed rain and soil seed banks limit native regeneration within urban forest restoration plantings in Hamilton City, New Zealand. New Zealand Journal Of Ecology 36:177-190.

P A Handford \& Associates Ltd 2009. Wellington City Council Re-vegetation Audit. Technical report, Wellington City Council.

Page HN, Bork EW 2005. Effect of planting season, bunchgrass species, and neighbor control on the success of transplants for grassland restoration. Restoration Ecology 13:651-658.

Parker GG 1995. Structure and microclimate of forest canopies, volume Lowman MD, Nadkarni NM (eds) Forest Canopies. Academic Press, Inc., San Diego, CA.

Parrish G 1984. Wildlife and wildlife sites of the Wellington Region. Fauna Survey Unit 38, New Zealand Forest Service.

Peek JM 1970. Relation of canopy area and volume to production of three woody species. Ecology 51:1098-1101. 
Pezeshki SR, Li S, Shields J F Douglas, Martin LT 2007. Factors governing survival of black willow (Salix nigra) cuttings in a streambank restoration project. Ecological Engineering 29:56-65.

Phillips C, Watson A 1994. Structural tree root research in New Zealand: A Review. 7. Manaaki Whenua Press.

Phillips CJ 2005. Erosion and sediment control using New Zealand native plants - what do we know? NZ Institute of Highway Technology.

Poole A, Adams N 1994. Trees and shrubs of New Zealand. Field guide series. Manaaki Whenua Press.

Porté A, Bartelink H 2002. Modelling mixed forest growth: a review of models for forest management. Ecological Modelling 150:141-188.

Porteous T 1993. Native forest restoration: a practical guide for landowners. Queen Elizabeth the Second National Trust.

Pratt C 1999. Factors affecting the establishment, growth and survival of native woody plant communities on the Canterbury Plain, New Zealand. Master's thesis, Lincoln University.

QEII National Trust 1997. Tips and techniques for forest restoration - part 2. Open Space 39.

R Development Core Team 2012. R: A Language and Environment for Statistical Computing. R Foundation for Statistical Computing, Vienna, Austria. URL http://www.R-project.org/.

Reinsch CH 1967. Smoothing by spline functions. Numerische mathematik 10:177-183.

Rietveld W 1989. Transplanting stress in bareroot conifer seedlings: its development and progression to establishment. Northern Journal of Applied Forestry 6:99-107. 
Ritchie H 2002. Guidelines for enhancing community conservation, based on the rural community conservation project. Technical report, Department of Conservation, Hamilton.

Rose AB, Frampton CM 1999. Effects of microsite characteristics on Hieracium seedling establishment in tall-and short-tussock grasslands, Marlborough, New Zealand. New Zealand Journal of Botany 37:107-118.

Sah JP, Ross MS, Koptur S, Snyder JR 2004. Estimating aboveground biomass of broadleaved woody plants in the understory of Florida Keys pine forests. Forest Ecology And Management 203:319-329.

Sakai A, Wardle P 1978. Freezing resistance of New Zealand trees and shrubs. New Zealand Journal of Ecology 1:51-61.

Sawyer J 2004. Plant conservation strategy Wellington Conservancy (excluding Chatham Islands). Technical Report 0-478-22580-6, Department of Conservation.

Shtatland ES, Cain E, Barton MB 2001. The perils of stepwise logistic regression and how to escape them using information criteria and the Output Delivery System. In: Proceedings of the Twenty-Sixth Annual SAS Users Group International Conference, 222-26. SAS Institute Inc, Cary, NC. URL http: //www2. sas. com/proceedings/sugi26/p222-26.pdf.

Silvertown J, Charlesworth D 2009. Introduction to Plant Population Biology. Wiley.

Simpson P 2001. Dancing leaves: the story of New Zealand's cabbage tree, tī kōuka. Canterbury University Press.

Smaill S, Ledgard N, Langer E, Henley D 2011. Establishing native plants in a weedy riparian environment. New Zealand Journal of Marine and Freshwater Research 45:357-367. 
Small DR 2004. Survival, breeding success and habitat selection of North Island robins Petroica Australis Longipes translocated to the Karori Wildlife Sanctuary. Master's thesis, Victoria University of Wellington, Wellington, New Zealand.

Sorensen P 2010. Annual soil quality monitoring report for the Wellington region, 2009/10. Technical Report GW/EMI-G-10/165, Environmental Monitoring and Investigations Department. Greater Wellington Regional Council.

Spiegelhalter DJ, Best NG, Carlin BP, Van Der Linde A 2002. Bayesian measures of model complexity and fit. Journal of the Royal Statistical Society: Series B (Statistical Methodology) 64:583-639.

Stephens C 2004. Plant succession, ecological restoration and the skinks of Stephens island / Takapourewa. Master's thesis, Victoria University of Wellington.

Stewart GH, Ignatieva ME, Meurk CD, Earl RD 2004. The re-emergence of indigenous forest in an urban environment, Christchurch, New Zealand. Urban Forestry \& Urban Greening 2:149-158.

Struve DK 2009. Tree establishment: A review of some of the factors affecting transplant survival and establishment. Arboriculture \& Urban Forestry 35:1013.

Sullivan JJ, Meurk C, Whaley KJ, Simcock R 2009. Restoring native ecosystems in urban Auckland: urban soils, isolation, and weeds as impediments to forest establishment. New Zealand Journal of Ecology 33:60-71.

Towns DR, Simberloff D, Atkinson IAE 1997. Restoration of New Zealand islands: Redressing the effects of introduced species. Pacific Conservation Biology 3:99-124.

Trammell TL, Schneid BP, Carreiro MM 2011. Forest soils adjacent to urban interstates: Soil physical and chemical properties, heavy metals, disturbance legacies, and relationships with woody vegetation. Urban Ecosystems 14:525$55^{2}$. 
Trotman R 2008. The benefits of community conservation: a literature review. Technical report, Auckland Regional Council.

Turner R 2013. National Climate Summary: Summer 2012/13. Technical report, NIWA National Climate Centre, Wellington.

Tyler CM, Davis FW, Mahall BE 2008. The relative importance of factors affecting age-specific seedling survival of two co-occurring oak species in southern California. Forest Ecology and Management 255:3063-3074.

Vallet J, Daniel H, Beaujouan V, Rozé F, Pavoine S 2010. Using biological traits to assess how urbanization filters plant species of small woodlands. Applied Vegetation Science 13:412-424.

Wardle P 1985. Environmental influences on the vegetation of New Zealand. New Zealand Journal of Botany 23:773-788.

Watson G 1996. Tree transplanting and establishment. Arnoldia.

Watson WT 2005. Influence of tree size on transplant establishment and growth. HortTechnology 15:118-122.

Watt MS, Davis MR, Clinton PW, Coker G, Ross C, Dando J, Parfitt RL, Simcock $\mathrm{R}$ 2008. Identification of key soil indicators influencing plantation productivity and sustainability across a national trial series in New Zealand. Forest Ecology and Management 256:180 - 190.

Watts $\mathrm{CH}$, Gibbs GW 2002. Revegetation and its effect on the ground-dwelling beetle fauna of Matiu-Somes Island, New Zealand. Restoration Ecology 10:96106.

Wellington City Council 2004. Wellington's Outer Green Belt Management Plan. Technical Report 1-877232-00-9, Wellington City Council.

Wellington City Council 2007. Biodiversity Action Plan. Technical report. 
Wilson D, Ruscoe W, Burrows L, McElrea L, Choquenot D, et al. 2006. An experimental study of the impacts of understorey forest vegetation and herbivory by red deer and rodents on seedling establishment and species composition in Waitutu Forest, New Zealand. New Zealand Journal of Ecology 30:191-207.

Yao X, Titus SJ, MacDonald SE 2001. A generalized logistic model of individual tree mortality for aspen, white spruce, and lodgepole pine in Alberta mixedwood forests. Canadian Journal of Forest Research 31:283-291. 
APPENDIX 1

I NUMBER OF SEEDLINGS TRANSPLANTED IN 2012 PER SITE

Sites Wineberry Cabbage tree Lemonwood

Cashmere Park

Chest hospital

Churton park

Derry hill

Finnimore st

Buckley Reserve Road

Homebush

Ian Galloway

Seton Nossiter Park

Woodridge
O

30

29

30

30

28

30

30

28

10
29

29

23

30

30

30

30

15

28

$\begin{array}{ll}0 & 30\end{array}$

30

o

19

30

12

7 


\section{CHARACTERISTICS OF THE SITES}

\begin{tabular}{|c|c|c|c|c|c|c|c|c|c|c|}
\hline & Cashmere PK & Chest Hosp & Churton PK & Derry hill & Finnimore St. & F.O.B.R. & Homebush PK & Ian Galloway PK & Seton Nossiter & Woodridge \\
\hline Agency & WCC & WCC & CG & WCC & WCC & CG & WCC & WCC & CG & CG \\
\hline Site area (ha) & 1.47 & 2.88 & 1.09 & 1.38 & 1.20 & 6.31 & 1.43 & 3.21 & 10.03 & 2.67 \\
\hline $\begin{array}{l}\text { Site characteristics before } \\
\text { re-vegetation started }{ }^{a}\end{array}$ & 1 & 2 & 3 & 1 & 1 & 4 & 4 & 4 & 1 & 1 \\
\hline Planting date & $22 / 05 / 13$ & $31 / 07 / 13$ & $29 / 06 / 13$ & $26 / 06 / 13$ & $26 / 06 / 13$ & $05 / 09 / 13$ & $22 / 05 / 13$ & $10 / 06 / 13$ & $02 / 08 / 13$ & $29 / 08 / 13$ \\
\hline Rainfall (mm) & 511.8 & 406.1 & 438.2 & 428.1 & 428.1 & 334.6 & 511.8 & 476.9 & 457.5 & 352.4 \\
\hline Rodents abundance (\%) & 16.6 & 0.0 & 16.6 & 16.6 & 0.0 & 16.6 & 16.6 & 50.0 & 0.0 & 0.0 \\
\hline McLean scale & 1 & 1 & 1 & 1 & 1 & 1 & 1 & 1 & 1 & 1 \\
\hline $\mathrm{PH}$ & 4.9 & 4.2 & 4.6 & $4 \cdot 3$ & $4 \cdot 5$ & 5.2 & 4.6 & 4.5 & $5 \cdot 5$ & 4.2 \\
\hline P content $(\mathrm{mg} / \mathrm{kg})$ & 7 & 5 & 22 & 9 & 11 & 19 & 8 & 9 & 7 & 5 \\
\hline $\mathrm{N}$ content $(\%)$ & 0.11 & 0.14 & 0.19 & 0.13 & 0.15 & 0.21 & 0.13 & 0.13 & 0.24 & 0.16 \\
\hline Soil compaction $\left(\mathrm{kg} / \mathrm{cm}^{2}\right)$ & 19.64 & 11.83 & 13.05 & 11.61 & 12.70 & 10.75 & 10.71 & 15.38 & 18.67 & 11.78 \\
\hline
\end{tabular}

a $\quad 1=$ Recreational park in residential area. $2=$ Backyard of inhabited public building. $3=$ Riparian roadside $.4=$ Old landfill. $5=$ Exotic forest 
3 MORTAlity PERCENTAgES AND SAMPLE Size ACROSS Sites

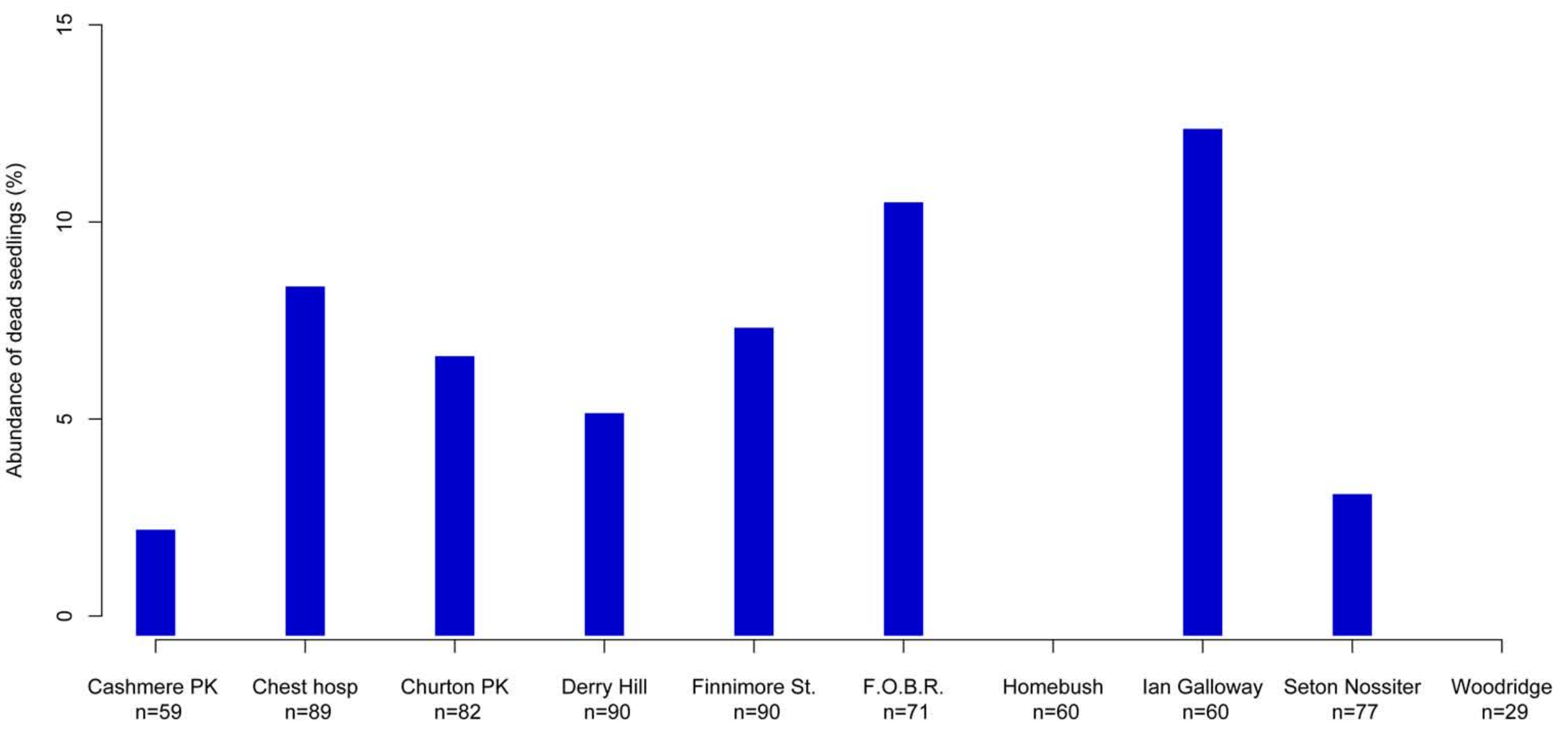


4 MOdel COMPARison AMONG THE OVERALl AND THE CATEgory MOdels

\begin{tabular}{|c|c|c|c|c|c|c|c|c|}
\hline Species & Model & Null model & AIC & Df & $\log$ Lik & $\begin{array}{l}\text { Number of } \\
\text { parameters }\end{array}$ & rel.lik & AIC weight \\
\hline \multirow{6}{*}{ Wineberry } & Overall & No & 143.11 & 7 & $-64 \cdot 56$ & 5 & 1.00 & 1.00 \\
\hline & Management & No & 157.94 & 4 & -74.97 & 2 & 0.00 & 0.00 \\
\hline & Relation & No & 160.74 & 5 & $-75 \cdot 37$ & 3 & 0.00 & 0.00 \\
\hline & Physical & No & 161.05 & 6 & $-74 \cdot 52$ & 4 & 0.00 & 0.00 \\
\hline & Soil & Yes & $164 \cdot 32$ & 6 & -76.16 & 4 & 0.00 & 0.00 \\
\hline & Seedling & Yes & 165.10 & 5 & $-77 \cdot 55$ & 3 & 0.00 & 0.00 \\
\hline \multirow{6}{*}{ Cabbage tree } & Overall & No & 86.81 & 10 & -33.40 & 7 & 1.00 & 0.65 \\
\hline & Physical & No & $89 \cdot 32$ & 6 & -38.66 & 4 & 0.28 & 0.18 \\
\hline & Relation & No & 89.87 & 5 & -39.94 & 3 & 0.22 & 0.14 \\
\hline & Seedling & No & 93.88 & 5 & -41.94 & 3 & 0.03 & 0.02 \\
\hline & Management & Yes & 95.24 & 4 & -43.62 & 2 & 0.01 & 0.01 \\
\hline & Soil & Yes & 97.81 & 6 & -42.90 & 4 & 0.00 & 0.00 \\
\hline
\end{tabular}


5 CORRELATION COEFFICIENTS OF HIGHLY CORRELATED FIXED EFFECTS FROM MORTALITY MODELS OF THE 2012 SEEDLINGS

Correlation coefficients of highly correlated fixed effects in wineberry mortality model

\begin{tabular}{lcccccc} 
Variable & Rainfall & Rodents & $\mathrm{pH}$ & $\mathrm{P}$ & $\mathrm{N}$ & Comp. \\
\hline Rodents abundance & -0.84 & & & & & \\
$\mathrm{pH}$ & 0.97 & -0.95 & & & & \\
$\mathrm{P}$ content & 0.76 & -0.99 & 0.90 & & & \\
N content & -0.79 & 1.00 & -0.91 & -1.00 & & \\
Soil Compaction & 0.29 & -0.77 & 0.52 & 0.84 & -0.82 & \\
Planting date & 0.87 & -1.00 & 0.97 & 0.98 & -0.99 & 0.72
\end{tabular}

Correlation coefficients of highly correlated fixed effects, excluding $\mathrm{N}$ content, in wineberry mortality model

\begin{tabular}{lcc} 
Variable & Rainfall & Comp. \\
\hline Soil compaction & -0.85 & \\
Planting date & 0.95 & -0.73
\end{tabular}


Correlation coefficients of the fixed effects, excluding $\mathrm{N}$ content and planting date, in wineberry mortality model

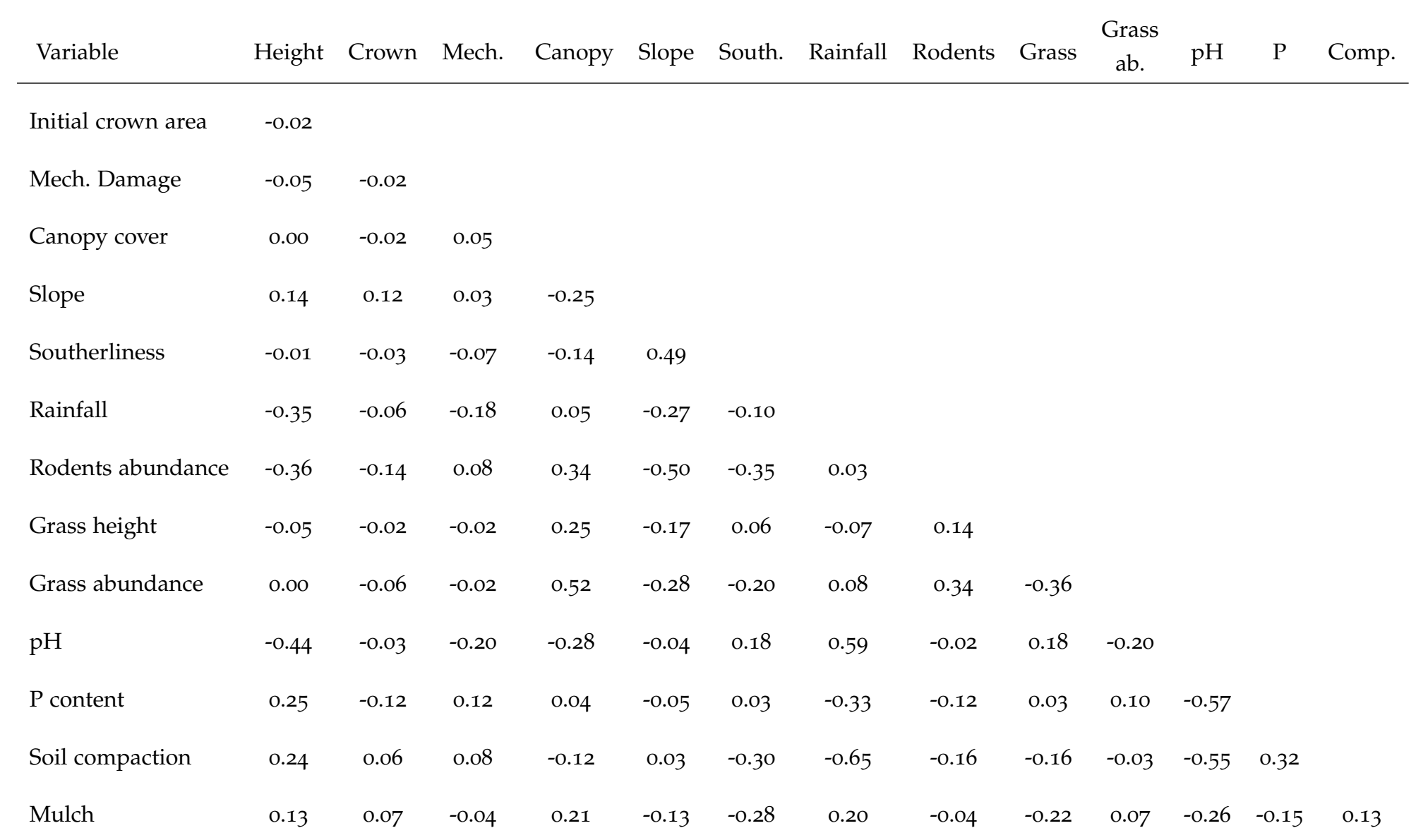


Correlation coefficients of highly correlated fixed effects in cabbage tree mortality model

\begin{tabular}{lcccc} 
Variable & Rainfall & P & N & Comp. \\
\hline P content & 0.64 & & & \\
N content & -0.74 & -0.90 & & \\
Soil compaction & -0.88 & -0.25 & 0.42 & \\
Planting date & 0.93 & 0.83 & -0.88 & -0.66
\end{tabular}

Correlation coefficients of highly correlated fixed effects, excluding planting date, in cabbage tree mortality model

\begin{tabular}{lccc} 
Variable & Rainfall & P & N \\
\hline P content & -0.81 & & \\
N content & 0.76 & -0.85 & \\
Soil compaction & -0.94 & 0.88 & -0.80
\end{tabular}

Correlation coefficients of highly correlated fixed effects, excluding planting date and soil compaction, in cabbage tree mortality model

\begin{tabular}{cc} 
Variable & $\mathrm{Ph}$ \\
\hline N content & -0.87
\end{tabular}


Correlation coefficients in the fixed effects, excluding planting date, soil compaction and $\mathrm{pH}$, in cabbage tree mortality model

\begin{tabular}{|c|c|c|c|c|c|c|c|c|c|c|c|c|}
\hline Variable & Height & Trunk & Mech. & Canopy & Slope & South. & Rainfall & Rodents & Grass & $\begin{array}{c}\text { Grass } \\
\text { ab. }\end{array}$ & $\mathrm{P}$ & $\mathrm{N}$ \\
\hline Initial trunk diameter & -0.42 & & & & & & & & & & & \\
\hline Mech. Damage & 0.06 & 0.01 & & & & & & & & & & \\
\hline Canopy cover & -0.02 & 0.08 & -0.07 & & & & & & & & & \\
\hline Slope & 0.01 & -0.18 & 0.24 & -0.25 & & & & & & & & \\
\hline Southerliness & -0.01 & -0.05 & 0.18 & 0.05 & -0.13 & & & & & & & \\
\hline Rainfall & -0.18 & 0.34 & -0.07 & 0.09 & 0.24 & -0.38 & & & & & & \\
\hline Rodents abundance & -0.33 & 0.32 & -0.14 & -0.02 & -0.54 & -0.30 & -0.16 & & & & & \\
\hline Grass height & 0.00 & 0.14 & 0.16 & 0.10 & -0.03 & -0.13 & 0.22 & -0.12 & & & & \\
\hline Grass abundance & -0.08 & -0.09 & -0.10 & 0.04 & 0.02 & -0.26 & 0.33 & 0.20 & -0.27 & & & \\
\hline P content & 0.08 & -0.20 & -0.18 & -0.30 & 0.04 & 0.44 & -0.07 & -0.35 & -0.22 & -0.21 & & \\
\hline $\mathrm{N}$ content & -0.02 & 0.23 & 0.07 & -0.18 & 0.11 & -0.57 & 0.35 & 0.38 & 0.24 & 0.12 & -0.53 & \\
\hline Mulch & 0.05 & 0.04 & 0.15 & 0.29 & 0.19 & 0.02 & 0.51 & -0.29 & 0.14 & 0.15 & -0.09 & -0.06 \\
\hline
\end{tabular}




\section{APPENDIX 2}

\section{NUMBER OF MONITORED SEEDLINGS TRANSPLANTED BETWEEN 2008 AND 2OII PER SITE}

Year planted Species Cashmere Chest Hosp. Churton PK Derry hill Finnimore St. F.O.B.R. Homebush Ian Galloway Onslow Coll. S.N.R.G. Woodridge Total Dead \%

\begin{tabular}{|c|c|c|c|c|c|c|c|c|c|c|c|c|c|c|c|}
\hline & Wineberry & 30 & 30 & 30 & 29 & 30 & 20 & 0 & 29 & 16 & 30 & 28 & 272 & 21 & $7 \cdot 7$ \\
\hline \multirow[t]{3}{*}{2011} & Cabbage tree & 30 & 14 & 7 & 30 & 30 & 0 & 0 & 21 & 23 & 30 & 14 & 199 & 11 & $5 \cdot 5$ \\
\hline & Lemonwood & 0 & 30 & 30 & 30 & 30 & 18 & 0 & 30 & 30 & 30 & 26 & 254 & 5 & 2.0 \\
\hline & Wineberry & 0 & 30 & 0 & 4 & 21 & 20 & 4 & 17 & 0 & 0 & 24 & 120 & 5 & 4.2 \\
\hline \multirow[t]{3}{*}{2010} & Cabbage tree & 0 & 30 & 0 & 0 & 0 & 1 & 30 & 30 & 0 & 21 & 28 & 140 & 5 & 3.5 \\
\hline & Lemonwood & 0 & 30 & 21 & 0 & 22 & 16 & 26 & 25 & 0 & 14 & 21 & 175 & 3 & 1.7 \\
\hline & Wineberry & 0 & 0 & 30 & 26 & 4 & 0 & o & 11 & 0 & 30 & 0 & 101 & 4 & 4.0 \\
\hline \multirow[t]{3}{*}{2009} & Cabbage tree & 0 & 0 & 19 & 30 & 0 & 0 & 0 & 0 & 0 & 9 & 0 & 58 & 1 & 1.7 \\
\hline & Lemonwood & 0 & 0 & 9 & 0 & 8 & 0 & 0 & 5 & 0 & 16 & 0 & 38 & 0 & 0.0 \\
\hline & Wineberry & 0 & 0 & 0 & 0 & 0 & 0 & o & 0 & 0 & 0 & 0 & o & 0 & 0.0 \\
\hline \multirow[t]{2}{*}{2008} & Cabbage tree & 0 & 0 & 10 & 0 & 30 & 0 & 0 & 0 & 0 & 0 & 0 & 40 & 7 & $17 \cdot 5$ \\
\hline & Lemonwood & 0 & 0 & 0 & 0 & 0 & 0 & 0 & 0 & 0 & 0 & 0 & 0 & 0 & 0.0 \\
\hline
\end{tabular}


CHARACTERISTICS OF THE SITES TRANSPLANTED BETWEEN 2008 AND 2011

Cashmere PK Chest Hosp Churton PK Derry hill Finnimore St. F.O.B.R. Homebush PK Ian Galloway PK Onslow Coll. Seton Nossiter Woodridge

\begin{tabular}{|c|c|c|c|c|c|c|c|c|c|c|c|}
\hline & Cashmere PK & Chest Hosp & Churton PK & Derry hill & Finnimore St. & F.O.B.R. & Homebush PK & Ian Galloway PK & Onslow Coll. & Seton Nossiter & Woodridge \\
\hline Agency & WCC & WCC & CG & WCC & WCC & CG & WCC & WCC & CG & CG & CG \\
\hline Site area (ha) & 1.47 & 2.88 & 1.09 & 1.38 & 1.20 & 6.31 & 1.43 & 3.21 & 1.97 & 10.03 & 2.67 \\
\hline $\begin{array}{l}\text { Site characteristics before } \\
\text { re-vegetation started }{ }^{1}\end{array}$ & 1 & 2 & 3 & 1 & 1 & 4 & 4 & 4 & 5 & 1 & 1 \\
\hline Initial measuring date & $28 / 05 / 12$ & $27 / 07 / 12$ & $03 / 07 / 12$ & $09 / 06 / 12$ & $11 / 07 / 12$ & $04 / 09 / 12$ & NA & $16 / 06 / 12$ & $08 / 07 / 12$ & $21 / 06 / 12$ & $19 / 07 / 12$ \\
\hline Rainfall (mm) & 511.8 & 420.9 & 446.6 & 476.8 & 440.5 & 340.1 & $\mathrm{NA}$ & $475 \cdot 3$ & 438.9 & 438.7 & 471.2 \\
\hline 2008-10 seedlings Initial measuring date & NA & $31 / 07 / 12$ & $03 / 07 / 12$ & $02 / 07 / 12$ & $11 / 07 / 12$ & $05 / 09 / 12$ & $28 / 05 / 12$ & $18 / 06 / 12$ & NA & $22 / 06 / 12$ & $28 / 07 / 12$ \\
\hline Rainfall (mm) & NA & 420.8 & 446.6 & 436.4 & 440.5 & 334.6 & 511.8 & 459.5 & NA & $425 \cdot 4$ & 420.9 \\
\hline Rodents abundance $(\%)$ & 16.6 & 0.0 & 16.6 & 16.6 & 0.0 & 16.6 & 16.6 & 50.0 & 16.6 & 0.0 & 0.0 \\
\hline $\mathrm{PH}$ & 4.9 & 4.2 & 4.6 & $4 \cdot 3$ & 4.5 & 5.2 & 4.6 & 4.5 & $4 \cdot 4$ & 5.5 & 4.2 \\
\hline $\mathrm{P}$ content $(\mathrm{mg} / \mathrm{kg})$ & 7 & 5 & 22 & 9 & 11 & 19 & 8 & 9 & 6 & 7 & 5 \\
\hline $\mathrm{N}$ content $(\%)$ & 0.11 & 0.14 & 0.19 & 0.13 & 0.15 & 0.21 & 0.13 & 0.13 & 0.12 & 0.24 & 0.16 \\
\hline Soil compaction $\left(\mathrm{kg} / \mathrm{cm}^{2}\right)$ & 19.64 & 11.83 & 13.05 & 11.61 & 12.70 & 10.75 & 10.71 & 15.38 & 14.76 & 18.67 & 11.78 \\
\hline
\end{tabular}


3 CORRELATION COEFFiCIENTS OF THE FIXED EFFECTS OF SEEDLINGS $\begin{array}{llll}\text { TRANSPLANTED } & \text { BETWEEN } & 2009 & \text { AND }\end{array}$

Correlation coefficients of the fixed effects of wineberry seedlings planted in 2011 model.

\begin{tabular}{lcc} 
variable & $\mathrm{N}$ & Comp. \\
\hline Soil compaction & 0.60 & \\
$\mathrm{pH}$ & -0.81 & -0.94
\end{tabular}


Correlation coefficients of the fixed effects, excluding $\mathrm{pH}$, of wineberry seedlings planted in 2011 model.

\begin{tabular}{|c|c|c|c|c|c|c|c|c|c|c|c|c|}
\hline Variable & Height & Crown & Mech. & C. cover & Slope & South & Rain & Rodents & Grass & Grass ab. & $\mathrm{N}$ & Comp. \\
\hline Initial crown area & -0.58 & & & & & & & & & & & \\
\hline Mech. Damage & -0.12 & 0.21 & & & & & & & & & & \\
\hline Canopy cover & -0.01 & -0.10 & -0.11 & & & & & & & & & \\
\hline Slope & -0.10 & -0.23 & -0.11 & -0.13 & & & & & & & & \\
\hline Southerliness & 0.02 & 0.03 & 0.14 & -0.00 & -0.40 & & & & & & & \\
\hline Rainfall & -0.14 & 0.25 & 0.02 & 0.39 & -0.19 & -0.16 & & & & & & \\
\hline Rodents abundance & -0.02 & -0.02 & 0.01 & 0.04 & 0.12 & -0.37 & 0.16 & & & & & \\
\hline Grass height & 0.22 & -0.22 & -0.27 & 0.04 & 0.13 & -0.11 & -0.09 & 0.29 & & & & \\
\hline Grass abundance & 0.03 & -0.20 & -0.06 & 0.06 & -0.02 & -0.00 & 0.02 & -0.04 & -0.08 & & & \\
\hline $\mathrm{N}$ content & -0.07 & 0.07 & 0.00 & 0.40 & -0.01 & -0.44 & 0.71 & 0.59 & 0.05 & 0.02 & & \\
\hline Soil compaction & -0.02 & -0.09 & -0.08 & -0.32 & 0.28 & -0.11 & -0.62 & -0.37 & 0.03 & 0.04 & -0.72 & \\
\hline P content & -0.20 & 0.28 & 0.05 & 0.22 & -0.37 & 0.49 & 0.34 & -0.46 & -0.37 & 0.03 & -0.12 & -0.04 \\
\hline Mulch & 0.00 & 0.00 & 0.00 & 0.00 & 0.00 & 0.00 & 0.00 & 0.00 & 0.00 & 0.00 & 0.00 & 0.00 \\
\hline
\end{tabular}


Correlation coefficients of the high correlated fixed effects of wineberry seedlings planted in 2009-10 model.

\begin{tabular}{lcccccc} 
Variable & C. cover & Rainfall & Rodents & $\mathrm{N}$ & Comp. & $\mathrm{P}$ \\
\hline Rainfall & 0.00 & & & & & \\
Rodents abundance & 0.00 & 0.90 & & & & \\
N content & 0.00 & 0.59 & 0.87 & & & \\
Soil compaction & 0.00 & -0.98 & -0.95 & -0.68 & & \\
P content & 0.00 & -0.80 & -0.94 & -0.80 & 0.90 & \\
Mulch & 0.97 & 0.00 & 0.00 & 0.00 & 0.00 & 0.00
\end{tabular}

Correlation coefficients of the high correlated fixed effects, excluding rodents abundance, of wineberry seedlings planted in 2009-10 model.

\begin{tabular}{lcccccc} 
Variable & C. cover & Rainfall & $\mathrm{pH}$ & $\mathrm{N}$ & Comp. & $\mathrm{P}$ \\
\hline Rainfall & -0.01 & & & & & \\
$\mathrm{pH}$ & -0.03 & 0.84 & & & & \\
N content & 0.04 & -0.68 & -0.97 & & & \\
Soil compaction & 0.01 & -0.71 & -0.98 & 1.00 & & \\
P content & -0.02 & 0.60 & 0.06 & 0.18 & 0.13 & \\
Mulch & 0.97 & -0.01 & -0.03 & 0.04 & 0.01 & -0.02
\end{tabular}


Correlation coefficients of the high correlated fixed effects, excluding rodents abundance and soil compaction, of wineberry seedlings planted in 2009-10 model.

\begin{tabular}{lcccccc} 
Variable & C. cover & South. & Rainfall & $\mathrm{pH}$ & $\mathrm{N}$ & $\mathrm{P}$ \\
\hline Slope & 0.14 & & & & & \\
Rainfall & -0.01 & -0.02 & & & & \\
pH & -0.18 & -0.25 & 0.97 & & & \\
N content & 0.58 & 0.80 & 0.52 & 0.30 & & \\
P content & -0.03 & -0.04 & 1.00 & 0.98 & 0.50 & \\
Mulch & 0.97 & 0.35 & -0.01 & -0.16 & 0.52 & -0.03
\end{tabular}

Correlation coefficients of the high correlated fixed effects, excluding rodents abundance, soil compaction and P content, of wineberry seedlings planted in 2009-10 model.

\begin{tabular}{lcccccc} 
Variable & C. cover & South. & Rainfall & Grass & $\mathrm{pH}$ & $\mathrm{N}$ \\
\hline Southerliness & 0.78 & & & & & \\
Rainfall & 0.99 & 0.81 & & & & \\
Grass height & -0.82 & -0.87 & -0.83 & & & \\
$\mathrm{pH}$ & -0.88 & -0.97 & -0.92 & 0.90 & & \\
$\mathrm{~N}$ content & 0.90 & 0.96 & 0.93 & -0.89 & -1.00 & \\
Mulch & 0.97 & 0.70 & 0.98 & -0.75 & -0.83 & 0.85
\end{tabular}


Correlation coefficients of the fixed effects, excluding rodents abundance, soil compaction, $\mathrm{P}$ content and $\mathrm{pH}$, of wineberry seedlings planted in 2009-10 model.

\begin{tabular}{|c|c|c|c|c|c|c|c|c|c|c|}
\hline Variable & Height & Crown & Mech. & Canopy & Slope & South & Rainfall & Grass & Grass ab. & $\mathrm{N}$ \\
\hline Initial crown area & -0.53 & & & & & & & & & \\
\hline Mech. Damage & 0.00 & 0.00 & & & & & & & & \\
\hline Canopy cover & -0.03 & 0.02 & 0.00 & & & & & & & \\
\hline Slope & -0.06 & 0.10 & 0.00 & -0.36 & & & & & & \\
\hline Southerliness & -0.03 & 0.06 & 0.00 & -0.03 & -0.53 & & & & & \\
\hline Rainfall & -0.36 & 0.07 & 0.00 & 0.41 & 0.30 & -0.28 & & & & \\
\hline Grass height & 0.47 & -0.09 & 0.00 & 0.03 & 0.02 & 0.08 & -0.02 & & & \\
\hline Grass abundance & -0.32 & -0.03 & 0.00 & -0.06 & 0.23 & 0.02 & 0.09 & -0.34 & & \\
\hline $\mathrm{N}$ content & -0.54 & 0.13 & 0.00 & -0.09 & 0.61 & -0.21 & 0.61 & -0.02 & 0.37 & \\
\hline Mulch & -0.48 & -0.05 & 0.00 & 0.21 & 0.17 & -0.17 & 0.66 & -0.25 & 0.64 & 0.52 \\
\hline
\end{tabular}


Correlation coefficients of the highly correlated fixed effects of cabbage tree seedlings planted in 2011 model.

\begin{tabular}{lcccccccc} 
Variable & C. cover & Slope & South & Rodents & $\mathrm{pH}$ & $\mathrm{N}$ & Comp. & $\mathrm{P}$ \\
\hline Slope & 0.86 & & & & & & & \\
Southerliness & -0.85 & -0.98 & & & & & & \\
Rodents abundance & 0.00 & 0.00 & 0.00 & & & & & \\
$\mathrm{pH}$ & 0.00 & 0.00 & 0.00 & 0.80 & & & & \\
$\mathrm{~N}$ content & 0.00 & 0.00 & 0.00 & -0.67 & -0.98 & & & \\
Soil compaction & 0.00 & 0.00 & 0.00 & -0.93 & -0.94 & 0.85 & & \\
P content & 0.00 & 0.00 & 0.00 & 0.22 & 0.60 & -0.69 & -0.37 & \\
Mulch & 0.00 & 0.00 & 0.00 & 0.81 & 0.81 & -0.70 & -0.87 & 0.53
\end{tabular}

Correlation coefficients of the highly correlated fixed effects, excluding $\mathrm{pH}$, of cabbage tree seedlings planted in 2011 model.

\begin{tabular}{lcccccccc} 
Variable & C. cover & Slope & South. & Rainfall & Rodents & $\mathrm{N}$ & Comp. & $\mathrm{P}$ \\
\hline Slope & 0.77 & & & & & & & \\
Southerliness & -0.74 & -0.98 & & & & & & \\
Rainfall & -0.19 & -0.25 & 0.24 & & & & & \\
Rodents abundance & 0.36 & 0.40 & -0.38 & -0.93 & & & & \\
N content & 0.68 & 0.77 & -0.75 & -0.70 & 0.86 & & & \\
Soil compaction & -0.18 & -0.11 & 0.08 & 0.82 & -0.91 & -0.70 & & \\
P content & 0.16 & 0.27 & -0.28 & 0.57 & -0.60 & -0.29 & 0.82 & \\
Mulch & 0.81 & 0.96 & -0.96 & -0.29 & 0.48 & 0.83 & -0.21 & 0.22
\end{tabular}

Correlation coefficients of the highly correlated fixed effects, excluding $\mathrm{pH}$ and southerliness, of cabbage tree seedlings planted in 2011 model.

\begin{tabular}{lc} 
Variable & $\mathrm{N}$ \\
\hline Soil Compaction & -0.91
\end{tabular}


Correlation coefficients of the fixed effects, excluding $\mathrm{pH}$, southerliness and soil compaction, of cabbage tree seedlings planted in 2011 model.

\begin{tabular}{|c|c|c|c|c|c|c|c|c|c|c|c|}
\hline Variable & Height & Trunk & Mec. & C. cover & Slope & Rainfall & Rodents & Grass & Grass ab. & $\mathrm{N}$ & $\mathrm{P}$ \\
\hline initial trunk diameter & -0.25 & & & & & & & & & & \\
\hline Mech. Damage & 0.10 & 0.23 & & & & & & & & & \\
\hline Canopy cover & -0.04 & 0.01 & 0.15 & & & & & & & & \\
\hline Slope & -0.29 & 0.12 & 0.10 & 0.27 & & & & & & & \\
\hline Rainfall & 0.22 & 0.05 & 0.08 & 0.11 & -0.06 & & & & & & \\
\hline Rodents abundance & 0.04 & 0.35 & -0.14 & -0.30 & -0.14 & -0.59 & & & & & \\
\hline Grass height & 0.33 & 0.13 & -0.06 & 0.15 & -0.45 & 0.15 & 0.09 & & & & \\
\hline Grass abundance & -0.63 & -0.08 & 0.00 & -0.04 & -0.11 & -0.14 & -0.20 & -0.18 & & & \\
\hline $\mathrm{N}$ content & -0.58 & -0.01 & -0.24 & 0.28 & 0.47 & -0.11 & 0.03 & 0.04 & 0.37 & & \\
\hline P content & -0.17 & -0.36 & -0.03 & -0.09 & 0.04 & -0.19 & -0.02 & -0.21 & 0.27 & 0.34 & \\
\hline Mulch & -0.09 & -0.10 & -0.01 & 0.23 & -0.18 & 0.22 & -0.17 & 0.44 & 0.37 & 0.50 & 0.34 \\
\hline
\end{tabular}

